\title{
Fairness, Trade, and Inequality
}

\author{
HARTMUT EGGER \\ UDO KREICKEMEIER
}

\section{CESIFO WORKING PAPER NO. 2344 \\ CATEgORY 7: TRAde POLICY \\ JULY 2008}

Presented at CESifo Area Conference on Global Economy, JANuARy 2008

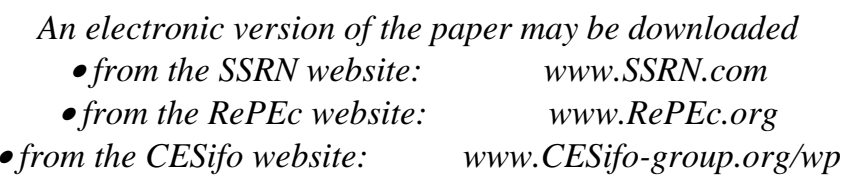




\title{
Fairness, Trade, and Inequality
}

\begin{abstract}
We develop a model of international trade between two symmetric countries that features inter-group inequality between entrepreneurs and workers, and also intra-group inequality within each of those two groups. Individuals in the economy are heterogeneous with respect to their entrepreneurial ability, and firms run by more able entrepreneurs have a higher productivity level and make higher profits. There is rent-sharing at the firm level due to fair wage preferences of workers, and hence firms with higher profits pay higher wages in equilibrium in order to elicit their workers' full effort. We show that in this framework international trade leads to a self-selection of the best firms into export status, and aggregate welfare increases if this selection effect is sufficiently strong. Gains from trade are accompanied by larger inequality along multiple dimensions: Involuntary unemployment and income inequality between entrepreneurs and workers increase, and so does inequality within these two subgroups of individuals, as measured by the respective Gini coefficients.
\end{abstract}

JEL Code: F12, F15, F16.

Keywords: heterogeneous firms, income inequality, fair wages, unemployment.

\author{
Hartmut Egger \\ University of Bayreuth \\ Department of Law and Economics \\ Universitätsstrasse 30 \\ 95447 Bayreuth \\ Germany \\ hartmut.egger@uni-bayreuth.de
}

\author{
Udo Kreickemeier \\ University of Nottingham \\ School of Economics \\ University Park \\ Nottingham NG7 2RD \\ United Kingdom \\ udo.kreickemeier@nottingham.ac.uk
}

9th June 2008

We are grateful to Simon Gächter, Steve Matusz, Peter Neary, Doug Nelson, Gianmarco Ottaviano and participants at the CESifo conference on Global Economy, the Göttingen Workshop on International Economics, and the Spring Meeting of the Midwest International Economics Group, as well as seminar participants at the Erasmus University of Rotterdam, the University of St. Gallen, the University of Nottingham and the University of Cyprus for helpful comments and suggestions. The major part of this paper was written while the first author was still working at the University of Zurich. 


\section{Introduction}

The recent literature on international trade with firm heterogeneity has substantially improved our understanding of the effects that market integration has on national economies. ${ }^{1}$ In this paper, we use it as the starting point for the re-assessment of a classic question in international economics: the impact of economic integration on the distribution of income within countries. We provide an integrated framework that features income inequality along multiple dimensions, and that is yet simple enough to allow the comprehensive analysis of the effects of international trade. In addition to income inequality between ability (or skill) groups, which has been the traditional concern of trade economists at least since the days of Stolper and Samuelson, we also look at income inequality within the same ability group. There is no doubt that in many countries intra-group inequality is an important part of overall inequality, and that it has increased substantially over the past decades (Katz and Autor, 1999; Barth and Lucifora, 2006; Autor, Katz and Kearney, 2008). The observed increase in intra-group inequality has been simultaneous to the widely documented surge in intermediate goods trade, and it is therefore important to treat this co-movement as an integral part of the overall relationship between economic integration and income distribution. ${ }^{2}$

When it comes to modelling intra-group wage inequality, two different approaches

\footnotetext{
${ }^{1}$ The most widely used theoretical framework is due to Melitz (2003). This model accounts for the stylised empirical fact that only the best firms export (see Clerides, Lach and Tybout, 1998; Bernard and Jensen, 1999). Important contributions that build on the Melitz framework include work by Helpman, Melitz and Yeaple (2004) and Bernard, Redding and Schott (2007). Alternative frameworks which account for firm heterogeneity in the context of trade are provided by Manasse and Turrini (2001), Bernard, Eaton, Jensen and Kortum (2003) and Melitz and Ottaviano (2008).

${ }^{2}$ While a positive relationship between the level of international outsourcing - which is usually measured by the share of intermediate goods imports in overall imports or gross production - and inter-group income inequality is well documented in the empirical trade literature (see e.g. Feenstra and Hanson, 1996, 1999; Geishecker and Görg, 2008), the link between intermediate goods imports and intra-group inequality has so far not been the focus of rigorous empirical analysis. This is surprising because the respective time patterns of the two phenomena suggest not only that this link may exist, but also that it may well be the most important channel through which economic integration affects income inequality.
} 
have been explored in the trade literature. The first is to consider a model where identical individuals perform different tasks in equilibrium. A setup of this type naturally generates intra-group income inequality if wages are task specific (Davidson, Matusz and Shevchenko, 2008). A second modelling strategy, and the one we are pursuing in the present paper, focuses on heterogeneity of firm characteristics and introduces a mechanism by which this heterogeneity translates into firm-specific wages. ${ }^{3}$ In previous contributions to this literature, inter-firm wage differentials have been determined by exogenous differences between firms in their monitoring technology (Davis and Harrigan, 2007) and their productivity (Egger and Kreickemeier, 2007), respectively. In the present paper, we model wages at the firm level as depending positively on operating profits (which are, of course, themselves endogenous). There is strong empirical support for the idea that larger, more productive firms, which are also the firms that export, pay higher wages (Bernard and Jensen, 1995, 1999). ${ }^{4}$ A positive relationship between firm size and wage payments is also well documented in the empirical labour economics literature. Blanchflower, Oswald and Sanfey (1996) and Bayard and Troske (1999) find this relationship using U.S. data and rigorously controlling for individual and job characteristics. More recently, Faggio, Salvanes and Van Reenen (2007) utilise panel data for the UK to show that firm productivity is a key determinant of individual wage inequality. The present model is compatible with these stylised facts since larger, more productive firms have higher operating profits as well.

Firm heterogeneity in our framework results from heterogeneous abilities of entrepreneurs. One entrepreneur, who acts as owner-manager, is needed to run each firm. Firms run by more able entrepreneurs are more productive, leading to higher operating profits

\footnotetext{
${ }^{3}$ Outside the field of international trade, a complementary approach to modelling intra-group wage inequality has focused on unobservable heterogeneity of individual characteristics like learning abilities (Aghion, Howitt and Violante, 2002).

${ }^{4}$ In a recent empirical study, Schank, Schnabel and Wagner (2007) confirm that firm characteristics are an important explanatory variable for individual wage inequality. Using a large set of linked employer-employee data from Germany, they show that a wage premium of exporters exists even if one controls for observable and unobservable characteristics of both individuals and the workplace.
} 
and thus to higher incomes for the respective entrepreneurs. We enrich this basic model structure and account for labour market imperfection, which we introduce by means of a fair wage-effort mechanism in the spirit of Akerlof and Yellen (1990). ${ }^{5}$ Workers' fair wage preferences lead to rent-sharing at the firm level: More able entrepreneurs, running firms with higher operating profits, have to pay their production workers higher wages in order to elicit full effort.

Taking stock, our model features income inequality along three dimensions. First, there is income inequality between different groups of individuals - entrepreneurs and production workers - that is determined by the ratio between the respective average incomes. Second, there is income inequality among entrepreneurs of differing abilities. And third, there is intra-group wage inequality among ex ante identical workers due to the fair wage-effort mechanism. Beyond that our model also features involuntary unemployment because the fair wage mechanism prevents wages from falling to the market clearing level. This contributes to the comprehensive picture of inequality as the unemployed typically receive a transfer payment which is lower than the income they could achieve if their abilities were used productively. In the model this payment is set equal to zero.

With regard to the determinants of inequality, we first look at the closed economy and analyse the role of fairness considerations, which are the source of labour market imperfection in our model. Thereby, we find that the more important the rent sharing motive is in workers' fair wage preferences, the smaller is the difference between the average income of entrepreneurs and the average income of production workers, and the less pronounced is the income inequality within the group of entrepreneurs. On the other hand, income inequality within the group of unskilled workers increases. Average productivity decreases, with adverse consequences for total output and aggregate employment.

With regard to the open economy, we make the standard assumption that there are fixed costs of exporting, and as a consequence not all firms find exporting worthwhile.

\footnotetext{
${ }^{5}$ There is considerable empirical support for a mechanism of this type, as illustrated in the review articles by Howitt (2002) and Bewley (2005). Both stress the wide extent and the strength of evidence from a range of sources that support the fair wage model. These sources include surveys of managers and workers, firm-level studies of pay and termination patterns, and experiments.
} 
International trade has two different selection effects: There is a self selection of the high productivity firms into export status, while at the other end of the productivity distribution firms shut down as the least able entrepreneurs realise better income opportunities elsewhere, e.g. by supplying their labour as production workers. This leads to an increase in aggregate unemployment and higher inequality between entrepreneurs and workers as well as within the groups of entrepreneurs and workers, respectively.

There are several contributions to the heterogeneous firm literature that look at the trade-inequality nexus which is also in the centre of this paper's interest. However, among these studies, Davidson, Matusz and Shevchenko (2008) is the only one that considers, as we do, both inter- and intra-group income inequality in an integrated framework. In their search and matching model with skilled and unskilled workers, and high- and low-tech firms, unskilled workers are matched with low-tech firms, while skilled workers can be matched with either high- or low-tech firms. Incomes of skilled workers are task-specific, i.e. they depend on the production technology used by their employer, and globalisation affects both the relative income of skilled workers in high- and low-tech firms and the relative income of skilled and unskilled workers.

Furthermore, there are some contributions that emphasise certain aspects of income inequality. Among them, there are three papers that address the effects of globalisation on the skill premium in a heterogeneous firm framework, while being silent on intragroup wage inequality. The paper closest to ours is Manasse and Turrini (2001). In their model, as in ours, each firm is run by an entrepreneur ("skilled worker") who has to hire homogenous unskilled ("raw") labour for the actual production process. The market for unskilled labour is assumed perfectly competitive, and therefore unskilled workers are paid the same wage in all firms. ${ }^{6}$ In Yeaple (2005), heterogeneous labour is the only factor of

\footnotetext{
${ }^{6}$ In addition, the number of firms, while endogenous in our model, is exogenous in Manasse and Turrini. As a direct consequence of this difference, globalisation has opposite effects on inter-group income inequality in the two models: While the relative income of entrepreneurs increases in our model, it falls in Manasse and Turrini (2001). See Meckl and Weigert (2007) for a contribution that endogenises the number of firms in a model of the Manasse-Turrini type with a distortion-free labour market. Their paper does not look at inequality but focuses on the question of skill formation.
} 
production, and globalisation affects the inequality between workers of differing skill levels. Bernard, Redding and Schott (2007) extend the heterogeneous firm model of Melitz (2003) to a two-sector, two-factor framework, and globalisation in their model has an effect on the relative return of the two factors of production.

Complementary to these papers, the models of Davis and Harrigan (2007) and Egger and Kreickemeier (2007) feature wage differences between identical workers in a Melitztype framework, but - with only one homogenous factor of production - are silent by construction on inter-group inequality between different groups of individuals (skilled and unskilled workers, or as in our case, workers and entrepreneurs). While both models are equipped in principle to discuss intra-group wage inequality, the analysis does not focus on sophisticated measures of income inequality but on other aspects of globalisation, like employment effects and the possible destruction of good jobs that offer high income opportunities for workers. Furthermore, while these papers emphasise one important channel through which trade liberalisation can influence intra-group wage inequality, namely firm selection, they do not account for another important channel, which is more closely related to the idea of rent sharing: With inter-firm wage inequality due to differences in exogenous parameters (monitoring technology or productivities, see above), these papers cannot discuss how trade liberalisation affects the wage profile, i.e. the relative wage paid by any two active firms, because this ratio is exogenous by construction. In our framework, wages are linked to firm profits, due to a rent-sharing motive of workers. Hence, trade liberalisation influences the wage profile as it affects firm profits asymmetrically.

The remainder of the paper is organised as follows. Section 2 develops the closed economy version of our model. Section 3 analyses the effects of international trade on the key variables of interest: welfare, unemployment and intra- as well as inter-group wage inequality. Section 4 concludes.

\section{Fair Wages and Firm Heterogeneity in a Closed Economy}

Consider an economy with a population of mass $N$. Two types of goods are produced: differentiated intermediate goods and homogeneous final output. 


\subsection{The Final Goods Sector}

Final output is a CES-aggregate of all available intermediate goods. We assume

$$
Y=\left[M^{-(1-\rho)} \int_{v \in V} q(v)^{\rho} d v\right]^{1 / \rho}, \quad 0<\rho<1,
$$

with the measure of set $V$ representing the mass of available intermediate goods $M$. In the (hypothetical) case where the final goods sector used an equal quantity $q$ of all intermediate inputs, the production technology in (1) would yield $Y=M q$, and hence increasing $M$ for a given aggregate level of input would not increase aggregate output. ${ }^{7}$

We take final output as the numéraire and assume perfect competition in the final goods market. The price index corresponding to the CES-aggregated good $Y$ is given by

$$
P=\left[M^{-1} \int_{v \in V} p(v)^{1-\sigma} d v\right]^{\frac{1}{1-\sigma}}
$$

with $\sigma \equiv 1 /(1-\rho)$ being the elasticity of substitution between the different varieties of intermediate goods. Due to the choice of numéraire, we have $P=1$. Using this normalisation, profit maximisation of competitive final goods producers leads to the following demand for variety $v$ :

$$
q(v)=\frac{Y}{M} p(v)^{-\sigma}
$$

\subsection{The Intermediate Goods Sector}

At the intermediate goods level, there is a continuum of monopolistically competitive firms, each producing a unique variety. Hence, the mass of intermediate goods producers equals $M$, the mass of varieties utilised by the final goods sector. When entering the market, each firm must set up its own distribution system, bearing a fixed cost $s f$, where $f$ is the quantity of distribution services used, and $s$ is the fee paid per unit. Once fixed

\footnotetext{
${ }^{7}$ Using technology (1) instead of the traditional Ethier (1982) technology, which features external scale economies, is attractive for two reasons. On the one hand, we avoid a negative relationship between country size and the unemployment rate, which would be counterfactual. And, on the other hand, we exclude trade effects that are merely driven by an increase in market size and are well understood for a long time. See Egger and Kreickemeier (2007) and Felbermayr, Prat and Schmerer (2007) for further discussion.
} 
cost $s f$ is incurred, output at the firm level $q$ is linear in labour input $l$ and depends on productivity level $\phi: q=\phi l$. Facing (3), firms choose the profit-maximising price

$$
p(\phi)=\frac{w(\phi)}{\rho \phi \varepsilon},
$$

with $w(\phi)$ denoting the wage paid to a physical unit of labour (a worker) in a firm with productivity $\phi$, and $\varepsilon$ being the effort level provided by workers. Hence, $w(\phi) /(\phi \varepsilon)$ is the marginal cost of a firm with productivity level $\phi$, and the price is a constant markup $1 / \rho$ over marginal cost. Combining (3) and (4), revenues of intermediate goods producers are given by

$$
r(\phi)=\frac{Y}{M}\left(\frac{w(\phi)}{\rho \phi \varepsilon}\right)^{1-\sigma}
$$

Furthermore, operating and total profits are given by $r(\phi) / \sigma$ and $\pi(\phi)=r(\phi) / \sigma-s f$, respectively.

Each firm in the intermediate goods sector is run by an entrepreneur, who acts as owner-manager of the firm. For the decision to become an entrepreneur, the individualspecific entrepreneurial ability as well as the available alternative income possibilities are relevant. Entrepreneurial ability $\phi$ is distributed according to a distribution function $G(\phi)$ with density $g(\phi)$, and a firm run by a more able entrepreneur has a higher labour productivity. For simplicity we assume that labour productivity in any given firm is equal to the entrepreneurial ability of its owner, and it can therefore be represented by the same variable, $\phi$. As is shown below, profits at the firm level $\pi(\phi)$ are increasing in a firm's productivity level, implying that an individual with a higher entrepreneurial ability can realise higher income as a firm owner.

If an individual decides against becoming an entrepreneur he can choose between two alternative activities. On the one hand, he can become self-employed, supplying one unit of distribution services at fee $s$. On the other hand, he can offer one unit of labour in the market for production workers. In neither role can the individual make productive use of his entrepreneurial ability. However, there is an important difference between these two alternative choices. While the market for services is perfectly competitive, leading to identical income streams of all service suppliers, the remuneration of production workers 
is uncertain because wages differ across firms and not all production workers actually find a job, due to labour market imperfections. The expected wage of a production worker is $(1-U) \bar{w}$, with $U$ being the unemployment rate of workers, and $\bar{w}$ the average wage of those who are employed. ${ }^{8}$

Individuals have to commit themselves to one of the three roles and cannot reverse their choices after entrepreneurs have made their investment and hiring decisions. ${ }^{9}$ In equilibrium, it has to be true that expected income from all three activities is the same. This implies

$$
\pi\left(\phi^{*}\right)=s=(1-U) \bar{w}
$$

where $\phi^{*}$ denotes ability of the marginal entrepreneur (i.e. the cutoff ability level). All variables in (6) are determined in general equilibrium.

\subsection{A Model of Inter-Firm Wage Differentiation}

The labour market in our model is characterised by a variant of the fair-wage effort mechanism identified by Akerlof and Yellen (1990). Workers have a preference for fairness and condition their effort $\varepsilon$ on the wage they are paid relative to the wage they consider to be fair, $\hat{w}$. If firms pay at least $\hat{w}$, workers provide the normal level of effort, which, for notational simplicity, is set equal to one. Effort decreases proportionally if the actual wage $w$ falls short of $\hat{w}$. Formally, we have $\varepsilon=\min (w / \hat{w}, 1)$. Due to $w / \varepsilon=\hat{w} \forall w \leq \hat{w}$, profit maximising firms have no incentive to pay less than $\hat{w}$, so that we can safely follow Akerlof

\footnotetext{
${ }^{8}$ Accounting for service provision as a third type of activity is not essential for our results. However, it allows in the simplest possible way to preserve in our framework one attractive feature that is present in any Melitz-type model: identical fixed costs across firms (with the same exporting status). Melitz (2003) assumed that the fixed input is provided by production workers. As noted by Egger and Kreickemeier (2007), this assumption is less attractive in a framework with firm-specific wages, because firms would then differ in both their fixed and their variable production costs. This in turn would make it difficult to disentangle the channels through which firm heterogeneity influences aggregate outcomes. For that reason, it is convenient to choose a different source for the provision of the fixed input.

${ }^{9}$ This is a standard assumption in a setting with certain and uncertain income streams (see e.g. Helpman and Itskhoki, 2007).
} 
and Yellen (1990) in assuming that firms set wages at least as high as $\hat{w}$. It is shown below that each firm can hire the profit maximising number of workers if they set $w=\hat{w}$, so this is what they do in equilibrium.

A key issue in this line of research is how to determine the fair wage. Fehr and Gächter (2000) point out that the idea of gift exchange, which underlies the fair wageeffort hypothesis, implies that firms that make higher profits pay higher wages as well. In order to build a model that takes this observation seriously, we need two ingredients: (i) firms that make different profits in equilibrium, and (ii) workers that consider profits of the firm they are employed by as a determinant of their fair wage. At this point, we focus on (ii), and - as far as (i) is concerned - simply postulate that in equilibrium firms differ in the profits they are making, deferring the derivation of this result to section 2.4.

In line with most of the existing literature on the fairness approach to efficiency wages, we assume that the fair wage is a weighted average of two factors, one being firm-internal and the other one being related to market forces. Similar to Kreickemeier and Nelson (2006), we associate the second component with the expected labour income per worker: $(1-U) \bar{w}$. The firm-internal component in determining the reference wage are operating profits $r(\phi) / \sigma .{ }^{10}$ The fair-wage constraint is given by

$$
\hat{w}(\phi)=\left(\frac{r(\phi)}{\sigma}\right)^{\theta}[(1-U) \bar{w}]^{1-\theta},
$$

where $\theta \in[0,1]$ can be interpreted as a rent-sharing parameter. Taking into account $\hat{w}(\phi)=w(\phi)$, the fair wage specification in (7) gives rise to identical wages in all firms if $\theta=0$ (cf. Melitz, 2003), while wages are firm-specific if $\theta>0 .{ }^{11}$

\footnotetext{
${ }^{10}$ Total profits would be an alternative to operating profits as the firm-internal component of the reference wage. The key mechanisms of our analysis do not depend on which of these measures of firm success is used, and choosing operating profits makes the model much more tractable. Danthine and Kurmann (2006) use a different firm-internal component and make the reference wage dependent on output per worker within a firm. While acknowledging the potential role of a firm internal reference point, their model does not allow for firm heterogeneity, implying that all firms within a sector pay the same wage.

${ }^{11}$ The fair wage approach to efficiency wages should be interpreted as a two-stage process, with firms offering a wage at stage one and workers deciding upon their effort level at stage two. Since it is not possible to write a binding contract on the effort of workers prior to the firm's wage offer, firms have no
} 


\subsection{Firm Distribution and Average Productivity}

Relative revenues (or operating profits) and wages of firms with different productivities $\phi_{1}$ and $\phi_{2}$ are jointly determined by eqs. (5) and (7):

$$
\frac{r\left(\phi_{1}\right)}{r\left(\phi_{2}\right)}=\left(\frac{w\left(\phi_{1}\right)}{w\left(\phi_{2}\right)}\right)^{1-\sigma}\left(\frac{\phi_{1}}{\phi_{2}}\right)^{\sigma-1} \quad \frac{w\left(\phi_{1}\right)}{w\left(\phi_{2}\right)}=\left(\frac{r\left(\phi_{1}\right)}{r\left(\phi_{2}\right)}\right)^{\theta}
$$

Both equations can be solved to give

$$
\frac{r\left(\phi_{1}\right)}{r\left(\phi_{2}\right)}=\left(\frac{\phi_{1}}{\phi_{2}}\right)^{\xi}
$$

with $\xi \equiv(\sigma-1) /[1+\theta(\sigma-1)]$, and substituting into eq. (5) implies

$$
\frac{p\left(\phi_{1}\right)}{p\left(\phi_{2}\right)}=\left(\frac{\phi_{1}}{\phi_{2}}\right)^{-\frac{\xi}{(\sigma-1)}} .
$$

By virtue of (3) and (10), more productive firms charge lower prices and realise a higher output level. Furthermore, it follows from (8) and (9), that they make higher profits and therefore pay higher wages, due to the fair-wage effort mechanism set out in section 2.3.

We can now determine a weighted average of productivity levels $\tilde{\phi}$ which is defined in a way to ensure that the quantity $q(\tilde{\phi})$ is equal to the average output per firm, $Y / M$. From (3), this implies $p(\tilde{\phi})=1$. Now, rewrite $(2)$ as $P=\left[\frac{1}{1-G\left(\phi^{*}\right)} \int_{\phi^{*}}^{\infty} p(\phi)^{1-\sigma} g(\phi) d \phi\right]^{\frac{1}{1-\sigma}}$, where $1-G\left(\phi^{*}\right)$ is the share of individuals with an entrepreneurial ability $\phi \geq \phi^{*}$. Using $P=p(\tilde{\phi})=1$ as well as $p(\phi)=p(\tilde{\phi})(\phi / \tilde{\phi})^{-\frac{\xi}{\sigma-1}}$ we get

$$
\tilde{\phi} \equiv\left[\frac{1}{1-G\left(\phi^{*}\right)} \int_{\phi^{*}}^{\infty} \phi^{\xi} g(\phi) d \phi\right]^{\frac{1}{\xi}} .
$$

We use the Pareto distribution to parametrise $G(\phi)$ :

$$
G(\phi)=1-\phi^{-k} \quad g(\phi)=k \phi^{-(k+1)},
$$

incentive to replace their workers by outsiders who declare they would be willing to work for a lower wage. The reason is that the wage considered fair by workers is firm-specific (see eq. (7)). This means that workers adjust their perception of a fair treatment (and thus the fair wage) to the (expected) operating profits of the firm they are working in. Fehr and Falk (1999) provide strong support for a mechanism of this type from laboratory experiments. 
where the lower bound of productivities is normalised to 1 without loss of generality (i.e. $\phi \geq 1)$, and $k$ is a strictly positive parameter. ${ }^{12}$ Substituting for $G\left(\phi^{*}\right)$ and $g(\phi)$ in (11) allows us to determine $\tilde{\phi}$ as a function of cutoff productivity $\phi^{*}$ :

$$
\tilde{\phi}=\left(\frac{k}{k-\xi}\right)^{1 / \xi} \phi^{*}
$$

In order to ensure a well defined average productivity for all admissible values of $\theta$, we assume $k>\sigma-1$ henceforth.

Denoting by $\bar{R}$ aggregate revenues in this economy and by $\bar{\Pi}$ aggregate profits we find analogous to Melitz (2003) - that $\bar{R}=\operatorname{Mr}(\tilde{\phi})$ and $\bar{\Pi}=M \pi(\tilde{\phi})$. Together with the previous results $P=p(\tilde{\phi})=1$ and (by definition) $Y=M q(\tilde{\phi})$, this illustrates the usefulness of the particular average defined in (11): The aggregate product market variables in our model are identical to what they would be if the economy hosted $M$ identical firms with productivity $\tilde{\phi}$.

\subsection{Equilibrium Factor Allocation}

The resource constraint ( $\mathrm{RC})$ of the economy is given by:

$$
L=N-(1+f) M
$$

with $L$ denoting the supply of production workers. RC is downward sloping in $M-L$ space as a higher number of firms, along with the individuals hired to provide distribution services for each firm, leaves fewer individuals for the labour supply.

A second relation between $L$ and $M$ can be derived by rewriting equilibrium condition (6). In a first step, using eqs. (9) and (13), this leads to

$$
r(\tilde{\phi}) \frac{k-\xi}{k \sigma(1+f)}=\rho \frac{Y}{L} .
$$

\footnotetext{
${ }^{12}$ Using firm level data for eleven European countries, Del Gatto, Mion and Ottaviano (2006) show that "Pareto is a fairly good approximation" (p. 17) of the productivity distribution in their data set. Due to its empirical support and its attractive features in terms of analytical tractability, the assumption of a Pareto distribution is by now common in the literature on heterogeneous firms. Prominent examples include Helpman, Melitz and Yeaple (2004) and Ghironi and Melitz (2005).
} 
The left hand side is the profit of the marginal firm, i.e. the income of the entrepreneur with cutoff ability level $\phi^{*}$. As shown in eq. $\left(6^{\prime}\right)$ it is a constant fraction of $r(\tilde{\phi})$, the revenues of the average firm. The right hand side equals the labour income per capita, as with markup pricing $\rho$ equals the labour share of aggregate income. Substituting $Y=\operatorname{Mr}(\tilde{\phi})$ and using $\rho=1-1 / \sigma$ we obtain the labour indifference condition (LI)

$$
L=\frac{k(\sigma-1)(1+f)}{k-\xi} M .
$$

Intuitively, for a given aggregate output a higher number of firms $M$ would imply a lower revenue of the average firm $r(\tilde{\phi})$, and consequently a lower profit of the marginal firm. In order to restore indifference of the marginal entrepreneur between running the firm and not doing so, the expected wage (which is proportional to aggregate output per worker) has to fall as well. Holding $Y$ constant, this requires an increase in labour supply $L$. Hence, LI is upward sloping in $M-L$ space.

The cutoff ability in our model is implicitly given by the relation $M=\left[1-G\left(\phi^{*}\right)\right] N$, and solving for $\phi^{*}$ yields

$$
\phi^{*}=\left(\frac{N}{M}\right)^{\frac{1}{k}} .
$$

Figure 1 plots eqs. (14), (15) and (16). The equilibrium values of $L$ and $M$ are determined by RC and LI in the right quadrant, and the implied value of $\phi^{*}$ can be read off the cutoff ability (CA) locus in the left quadrant. Solving for the three endogenous variables, we get:

$$
\begin{aligned}
L & =\frac{k \sigma-k}{k \sigma-\xi} N \\
M & =\frac{k-\xi}{(k \sigma-\xi)(1+f)} N \\
\phi^{*} & =\left(\frac{(k \sigma-\xi)(1+f)}{k-\xi}\right)^{\frac{1}{k}}
\end{aligned}
$$

It is immediate from eqs. (17) to (19) that an increase in rent sharing parameter $\theta$ increases $M$, while reducing $L$ and $\phi^{*}$. Hence, a stronger rent-sharing motive of workers increases the number of entrepreneurs (or, equivalently, the number of firms). The logic is as follows: With a higher value of $\theta$, more productive firms have to pay relatively higher 


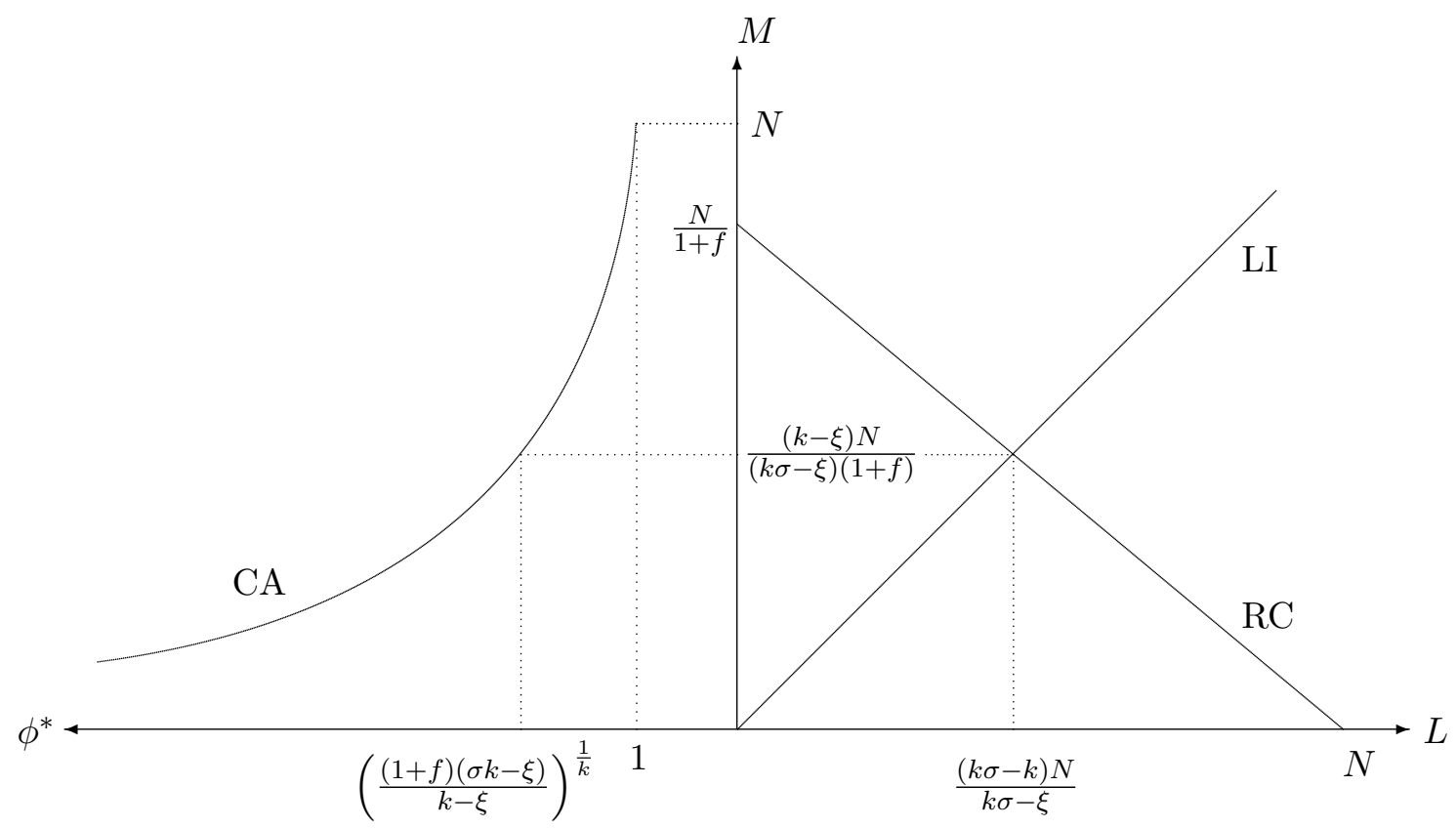

Figure 1: Equilibrium in the closed economy

wages, thereby giving a relative advantage, ceteris paribus, to less productive firms (less able entrepreneurs). The impact of $\theta$ on $M, L$ and $\phi^{*}$ can also be seen in figure 1 , where an increase in $\theta$ rotates the LI locus counter-clockwise, leaving the other two curves unaffected.

\subsection{Welfare and Unemployment}

In our model with a single homogeneous final good, per capita income $Y / N$ is the natural utilitarian welfare measure. Since we have already derived the proportion of workers in the population, $L / N$, in eq. (17), we now turn to deriving the output per worker, $Y / L$. The fair wage constraint for the firm with average productivity equals $w(\tilde{\phi})=(r(\tilde{\phi}) / \sigma)^{\theta}(\rho Y / L)^{1-\theta}$. Substitution from eq. $\left(6^{\prime}\right)$ yields

$$
w(\tilde{\phi})=\rho\left(\frac{k(1+f)}{k-\xi}\right)^{\theta} \frac{Y}{L}
$$


and hence the wage of the average firm is proportional to the income per worker. Combining eq. (20) with the optimal pricing rule for the average firm, $w(\tilde{\phi}) /(\rho \tilde{\phi})=1$, gives

$$
\frac{Y}{L}=\left(\frac{k-\xi}{k(1+f)}\right)^{\theta} \tilde{\phi},
$$

and using eq. (17), this leads to welfare in the closed economy

$$
\frac{Y}{N}=\frac{k \sigma-k}{k \sigma-\xi}\left(\frac{k-\xi}{k(1+f)}\right)^{\theta} \tilde{\phi}
$$

where $\tilde{\phi}$ is determined by eqs. (13) and (19). Hence, all other things equal welfare increases proportionally with the productivity of the average firm.

To determine the equilibrium unemployment rate, we can use the adding-up condition that aggregate employment has to equal the sum of the employment levels of all firms:

$$
(1-U) L=\frac{M}{1-G\left(\phi^{*}\right)} \int_{\phi^{*}}^{\infty} l(\phi) g(\phi) d \phi
$$

Accounting for $M l(\tilde{\phi})=M q(\tilde{\phi}) / \tilde{\phi}=Y / \tilde{\phi}$ and using eq. (21), this can be rewritten as

$$
1-U=\left(\frac{1}{1+f}\right)^{\theta} \frac{k-\xi}{k-(1-\theta) \xi} .
$$

There is full employment if the wage considered to be fair by workers does not hinge on the operating profit of the firm they are working in, i.e. $U=0$ if $\theta=0$. In the case of interest, namely $\theta>0$, we get $U \in(0,1)$.

With eqs. (22) and (23) at hand, we can now look at the comparative-static effects of a change in the rent-sharing parameter $\theta$ on welfare and unemployment. The respective results are summarised in the following proposition.

Proposition 1. An increase in $\theta$ lowers per capita income $Y / N$ and increases the unemployment rate $U$.

Proof. See Appendix

There are counteracting effects of a $\theta$ increase on the equilibrium unemployment rate. Holding aggregate variables constant, an increase in the rent-sharing parameter raises the reference wage of all workers, according to (7), and even more so in the more productive 
firms, thereby initially reducing employment in all firms. This employment reduction lowers aggregate labour income and therefore works against the direct effect of a $\theta$ increase on the reference wage. For the least productive firms, it is the indirect effect that dominates, thereby triggering firm entry at the bottom end of the ability distribution. As noted in section 2.5 this lowers labour supply $L$. For the most productive firms, however, it is the direct effect that dominates, implying a destruction of the "good jobs" that pay high wages (Davis and Harrigan, 2007). Overall, employment loss in the most productive firms is not fully compensated by additional employment in the least productive firms (including the new entrants), and aggregate employment falls by more than the labour supply, leading to an increase in $U$. Aggregate output falls due to both the decrease in aggregate employment and the shift in employment towards less productive firms. As a consequence, per capita income $Y / N$ unambiguously falls after a $\theta$ increase.

\subsection{Income Distribution}

After deriving aggregate measures to characterise the equilibrium in the closed economy, we now turn to characterising the income distribution. There is more than one way of looking at this question, considering that we have three groups of people in the economy (entrepreneurs, self-employed individuals and workers), and that there is income inequality within the group of entrepreneurs and within the group of workers. As the focus of most existing studies is on inter-group inequality (see Bernard, Redding and Schott, 2007, for a recent contribution in the context of heterogeneous firms), we first consider the ratio of average entrepreneurial income $\bar{\pi}$ and the average income of workers $(1-U) \bar{w}$, with the latter being equal to service fee $s$. This ratio is given by ${ }^{13}$

$$
\frac{\bar{\pi}}{(1-U) \bar{w}}=\frac{k+f \xi}{k-\xi} \equiv \omega(\xi)
$$

\footnotetext{
${ }^{13}$ Note that aggregate profits are given by $\bar{\Pi}=M[r(\tilde{\phi}) / \sigma-f(1-U) \bar{w}]$, while average profits equal $\bar{\pi}=\bar{\Pi} / M$. Accounting for $(1-U) \bar{w}=r\left(\phi^{*}\right) /[\sigma(1+f)]$ and $r(\tilde{\phi}) / r\left(\phi^{\star}\right)=k /(k-\xi)$, one can easily calculate
} $(24)$. 
Note that $\omega(\xi)>1 .{ }^{14}$ This is intuitive as average profits $\bar{\pi}$ are higher than profits of the least productive firms $\pi\left(\phi^{*}\right)$, while the marginal entrepreneur is indifferent between setting up a firm or supplying its labour in the market for production workers, i.e. $\pi\left(\phi^{*}\right)=$ $(1-U) \bar{w}$, according to $(6)$.

To determine intra-group inequality, we calculate the Gini coefficients for entrepreneurial and labour income. ${ }^{15}$ As it is shown in detail in the Appendix, the Gini coefficient for the group of entrepreneurs is given by

$$
A_{M}=\frac{k \xi(1+f)}{(k+\xi f)(2 k-\xi)}
$$

while the Gini coefficient for (employed) production workers is given by

$$
A_{L}=\frac{\theta \xi}{2(k-\xi)+\theta \xi} .
$$

Comparing (25) and (26), we obtain $A_{M}>A_{L}$, so that the inequality of entrepreneurial income is more pronounced than the inequality of labour income, according to the Gini criterion. $^{16}$

\footnotetext{
${ }^{14}$ Combining (23) and (24) we can determine $\bar{\pi} / \bar{w}=[1 /(1+f)]^{\theta}(k+f \xi) /[k-(1-\theta) \xi]$ as an alternative measure of inter-group income inequality. However, as $(1-U) \bar{w}$ is the relevant criterion when deciding upon setting up a firm, we choose the ratio in (24) as our preferred measure of inter-group inequality.

${ }^{15}$ The Gini coefficient is a widely used measure for inequality. It is given by $A=1-2 \int_{0}^{1} Q(\gamma) d \gamma$, with $Q(\gamma)$ being the Lorenz curve, which determines the share of (profit or labour) income attributed to the bottom $\gamma$ percent of individuals in the reference group (entrepreneurs or employed workers). Put differently, the Gini coefficient describes the area between the Lorenz curve and the diagonal in a Lorenz diagram (multiplied by 2). It takes a value between 0 and 1 , with higher values of $A$ reflecting higher inequality.

${ }^{16}$ In a robustness analysis, we have grouped together entrepreneurs and self-employed service providers to obtain an inequality measure for the "independent civilian labour force". However, as the respective Gini calculations for income inequality of this somewhat more comprehensive group of individuals did not provide any additional insights, we do not discuss them here. Furthermore, since accounting for unemployed workers (who earn zero income) would not change our results, we exclude them from the analysis when calculating the Gini coefficient for labour income. Ignoring self-employed and unemployed individuals when talking about intra-group inequality implies that the Lorenz curves, underlying the Gini coefficients in (25) and (26), are strictly increasing and strictly convex functions in the respective Lorenz diagrams.
} 
With equations (24)-(26) at hand, we can now determine the impact of an increase in rent-sharing parameter $\theta$ on income inequality. The results are summarised in the following proposition.

Proposition 2. An increase in $\theta$ lowers both inter-group inequality $\omega(\xi)$ and the Gini coefficient for entrepreneurial income $A_{M}$. An increase in $\theta$ increases the Gini coefficient for labour income $A_{L}$.

Proof. See Appendix.

A higher $\theta$ increases the weight of the firm-specific component in the wage considered to be fair by workers (see (7)). This raises the variable production costs of more productive firms relative to their less productive competitors. As a consequence, the differential of revenues in (9) declines and so does profit inequality $A_{M}$. Furthermore, with the expected income of production workers being linked to the income of the marginal entrepreneur, according to indifference condition (6), the decline in profit inequality $A_{M}$ induces a fall in inter-group inequality $\omega(\xi)$. A higher weight of the firm-specific component in the reference wage of workers tends to increase the inequality of labour income. This effect is reinforced by the entry of less productive firms. However, there is also a counteracting effect, as an increase in the variable production costs of more productive firms relative to their less productive competitors lowers the market share (and thus the employment share) of these firms. All other things equal, this tends to reduce income inequality of production workers. The latter effect is dominated by the first two ones, however, so that the Gini coefficient for labour income goes up. By striving harder to get their fair share of firms' profits, workers therefore increase inequality within their group. This completes our discussion of the autarky scenario.

\section{The Open Economy}

We now look at the trade equilibrium in a world of two identical countries. As in the standard Melitz model, there are two types of trade costs: variable transport costs of the iceberg type, represented by parameter $\tau>1$, and fixed export costs. Fixed export costs 
are associated with the necessity of a local distribution system in the foreign economy. The required amount of $f_{x}$ units of service inputs is again contracted to self-employed individuals. Because these individuals have the choice between working for either type of firm (exporter or non-exporter), their remuneration in either role has to be the same in equilibrium, and fixed export costs become $s f_{x}$.

\subsection{Partitioning of Firms by Export Status}

The analysis focuses on the empirically relevant case where not all firms are exporters, and hence there is self-selection of firms into export status. In order to find the exact condition for this to hold in equilibrium, we have to take into account that with the specification of the fair wage constraint in eq. (7) a firm with higher operating profits has to pay a higher wage, and hence an exporter pays higher wages than a non-exporter ceteris paribus.

This implies that in the open economy the revenue differential between two firms does not only depend on their relative productivity levels but also on their respective export status. We therefore have to distinguish between domestic revenues of exporters and nonexporters. With the former serving consumers in more than one market and the latter serving only domestic consumers (and thus being active in one market), we use superscripts $m$ and $o$, respectively, to indicate revenues of these two firm types. In the case of exporting firms, we also have to distinguish between revenues associated with domestic and foreign sales, using subscript $x$ to denote the latter. For an exporting firm with productivity level $\phi$ and revenues in its home market of $r^{m}(\phi)$, revenues from exporting are given by $r_{x}^{m}(\phi)=\tau^{1-\sigma} r^{m}(\phi)$.

In analogy to eq. (8), the home market revenue differential of two firms that have identical productivity but differing export status is jointly determined by

$$
\frac{w^{m}}{w^{o}}=\left[\left(1+\tau^{1-\sigma}\right) \frac{r^{m}}{r^{o}}\right]^{\theta} \quad \text { and } \quad \frac{r^{m}}{r^{o}}=\left(\frac{w^{m}}{w^{o}}\right)^{1-\sigma} \text {. }
$$

Both equations can be solved to give

$$
\frac{r^{m}}{r^{o}}=\left(1+\tau^{1-\sigma}\right)^{-\theta \xi}<1 .
$$


Hence, a firm of a given productivity has lower revenue in its home market if it chooses to become an exporter because the higher operating profits that exporting entails lead to higher wages via the fair wage constraint, and therefore higher marginal cost. The relative gross gain from exporting (RGE) of a firm with productivity $\phi$ is then given by

$$
\frac{\left(1+\tau^{1-\sigma}\right) r^{m}(\phi)-r^{o}(\phi)}{r^{o}(\phi)}=\left(1+\tau^{1-\sigma}\right)^{\frac{\xi}{\sigma-1}}-1 .
$$

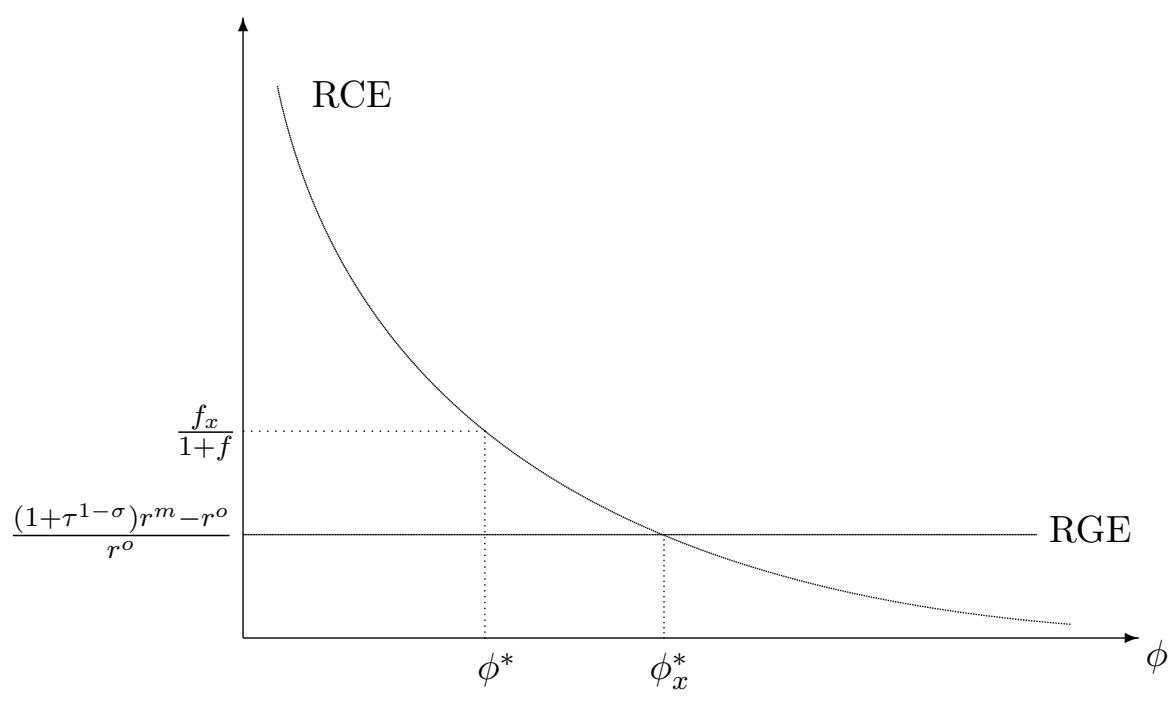

Figure 2: Determination of domestic and export cutoff productivities

The relative costs of entering the export market (RCE), also measured as a proportion of a non-exporter's operating profits, are given by $s f_{x} \sigma / r^{o}(\phi)$. Figure 2 shows the RGE and RCE loci, and the marginal exporter with productivity $\phi_{x}^{*}$ is found at the intersection of the two loci. Using eq. (6) to substitute for $s$, we find that for the marginal firm, i.e. the firm with productivity $\phi^{*}$, RCE equals $f_{x} /(1+f)$, and hence the necessary and sufficient condition for the export selection effect to be present is given by

$$
\frac{f_{x}}{1+f}>\left(1+\tau^{1-\sigma}\right)^{\frac{\xi}{\sigma-1}}-1 .
$$

It is assumed throughout that this condition holds. 


\subsection{The Share of Exporters and Average Productivity}

Figure 2 does not allow us to pin down the two cutoff levels $\phi^{*}$ and $\phi_{x}^{*}$ explicitly, because $s$ - and therefore the position of the RCE locus - is not yet determined. However, we can still derive the fraction of firms that export $\chi$, which depends only on the ratio of the two cutoff levels: As the mass of exporting firms and the mass of all firms are given by $1-G\left(\phi_{x}^{*}\right)$ and $1-G\left(\phi^{*}\right)$, respectively, with the assumption of Pareto-distributed productivities it follows that $\chi=\left[1-G\left(\phi_{x}^{*}\right)\right] /\left[1-G\left(\phi^{*}\right)\right]=\left(\phi^{*} / \phi_{x}^{*}\right)^{k}$. Furthermore we have, using eq. (28),

$$
\frac{r^{o}\left(\phi_{x}^{*}\right)}{\sigma}\left[\left(1+\tau^{1-\sigma}\right)^{\frac{\xi}{\sigma-1}}-1\right]=s f_{x} \quad \text { and } \quad \frac{r^{o}\left(\phi^{*}\right)}{\sigma}=s(1+f),
$$

where the first expression states that the additional operating profits the marginal exporting firm makes under exporting have to equal the fixed exporting cost, and the second expression is just a rewritten version of the indifference condition (6) for the marginal entrepreneur. Lastly, in analogy to eq. (9) we can relate the relative productivities of the firms at the two cutoffs to their relative operating profits (or revenues): $\left(\phi^{*} / \phi_{x}^{*}\right)^{\xi}=r^{o}\left(\phi^{*}\right) / r^{o}\left(\phi_{x}^{*}\right)$. Putting together all these expressions leads to

$$
\chi=\left(\frac{\phi^{*}}{\phi_{x}^{*}}\right)^{k}=\left[\left(\left(1+\tau^{1-\sigma}\right)^{\frac{\xi}{\sigma-1}}-1\right) \frac{1+f}{f_{x}}\right]^{\frac{k}{\xi}},
$$

and one can immediately see that $\chi$ is strictly decreasing in both $\tau$ and $f_{x}$, as can be expected. With both countries being symmetric, the total number of producers selling to one market is given by $M_{t}=M(1+\chi)$.

It was shown above that for the closed economy we can look at a firm with average productivity $\tilde{\phi}_{a}$ (subscript $a$ is used henceforth to denote autarky values) when determining aggregate variables. In the open economy with self-selection of firms into export status it is useful to distinguish between two average productivities that use different weights in the aggregation of firm productivities. We denote by $\tilde{\phi}$ the average productivity of domestic firms using (hypothetical) output shares that would result if firms were paying wages that reflect their domestic (rather than total) operating profits. While these output shares are not actually observed in the open economy, the average is still very useful because it is proportional to the cutoff productivity $\phi^{*}$ according to eq. (13). We also 
define a weighted productivity average of all firms selling in a particular market, $\tilde{\phi}_{t}$. This productivity accounts for the fact that exporters pay higher wages than non-exporters and that international trade involves transportation costs. In analogy to the closed economy, we formulate $\tilde{\phi}_{t}$ in a way to ensure $q^{o}\left(\tilde{\phi}_{t}\right)=Y / M_{t}$, i.e. the quantity produced by the average firm for its domestic market - provided this firm is a non-exporter - equals the average output per firm selling to this market. ${ }^{17}$ In analogy to the average productivity in the closed economy $\tilde{\phi}_{a}$, the definition of $\tilde{\phi}_{t}$ furthermore implies $P=p^{o}\left(\tilde{\phi}_{t}\right)=1$ and $Y=\bar{R}=M_{t} r^{o}\left(\tilde{\phi}_{t}\right)$. Hence, for the determination of aggregate product market variables in the open economy version of the model $\tilde{\phi}_{t}$ assumes the role that $\tilde{\phi}_{a}$ has for the closed economy.

It is shown in the appendix that $\tilde{\phi}_{t}$ and $\tilde{\phi}$ are related by

$$
\tilde{\phi}_{t}=\tilde{\phi}\left(\frac{\Delta}{1+\chi}\right)^{\frac{1}{\xi}}
$$

where $\Delta \equiv\left(1+f+\chi f_{x}\right) /(1+f)$ is the ratio of fixed resource requirements of the respective average firms under trade and autarky. In general it is ambiguous which of the two average productivities is larger. There are three effects that determine their relative size, and they work in opposite directions. The export selection effect increases $\tilde{\phi}_{t}$, ceteris paribus, as only the most productive foreign firms export, thereby increasing the share of high productivity firms in the average. The remaining two effects both work to decrease $\tilde{\phi}_{t}$ relative to $\tilde{\phi}$ : The lost in transit effect caused by goods melting away en route reduces the share of foreign exporters in overall domestic sales. The exporter wage premium effect reduces the share of foreign and domestic exporters in overall domestic sales, as exporting firms have to pay higher wages than non-exporters with the same productivity because their profits are higher. Both effects lower the average as they reduce the weight of high productivity firms. It is immediate from eq. (31) that $\tilde{\phi}_{t}=\tilde{\phi}$ if and only if $f_{x}=1+f$. With $f_{x}$ exceeding $1+f$ the export selection effect dominates, and hence we get $\tilde{\phi}_{t}>\tilde{\phi}$, while the reverse ranking of the two average productivities holds if $f_{x}$ is smaller than $1+f$, and

\footnotetext{
${ }^{17}$ This definition of $\tilde{\phi}_{t}$ does not imply that a firm with productivity $\tilde{\phi}_{t}$ is actually a non-exporter. If this firm was an exporter, its output in the domestic market would be $q^{m}\left(\tilde{\phi}_{t}\right)<q^{o}\left(\tilde{\phi}_{t}\right)=Y / M_{t}$ due to the wage premium it would have to pay in this case (see the discussion in section 3.1).
} 
hence the export selection effect is weakened.

The implied revenue differential follows from eq. (9) as $r^{o}\left(\tilde{\phi}_{t}\right) / r^{o}(\tilde{\phi})=\Delta /(1+\chi)$, and multiplying both sides by $M$ leads to

$$
M_{t} r^{o}\left(\tilde{\phi}_{t}\right)=M \Delta r^{o}(\tilde{\phi})
$$

The left hand side of eq. (32) equals aggregate output $Y$ in the open economy. It is equal to the aggregate output of a closed economy with fixed resource requirements which are a multiple $\Delta$ of the domestic fixed resource requirements, $1+f$. This is intuitive, since $(1+f) \Delta$ equals the average fixed resource requirements (including those for exporting) in the open economy.

\subsection{Equilibrium Factor Allocation}

In analogy to the autarky scenario, we can now determine the productivity of the marginal firm, $\phi^{*}$, the mass of entrepreneurs $M$ and the supply of labour $L$. The resource constraint for the open economy is given by

$$
\mathrm{RC}_{\mathrm{t}}: \quad L=N-(1+f) \Delta M
$$

Equilibrium condition $\left(6^{\prime}\right)$ from the closed economy equilibrium still holds, with $r^{o}(\tilde{\phi})$ replacing $r(\tilde{\phi})$. Using $Y=M \Delta r^{o}(\tilde{\phi})$, the labour indifference condition for the open economy can then be written as

$$
\mathrm{LI}_{\mathrm{t}}: \quad L=\frac{k(\sigma-1)(1+f) \Delta}{k-\xi} M
$$

The relationship between $\phi^{*}$ and $M$ is unchanged and given by eq. (16).

All three loci are represented in figure 3, where the respective loci from the closed economy are represented by dotted lines. The RC locus rotates counter-clockwise because in the open economy the fixed resource requirement of firms is higher on average (by a factor $\Delta$ ) due to fixed export costs, and hence for a given number of firms the number of available workers decreases. The LI locus on the other hand rotates clockwise: Holding $Y$ constant, a given number of firms would be associated with a lower domestic revenue of 


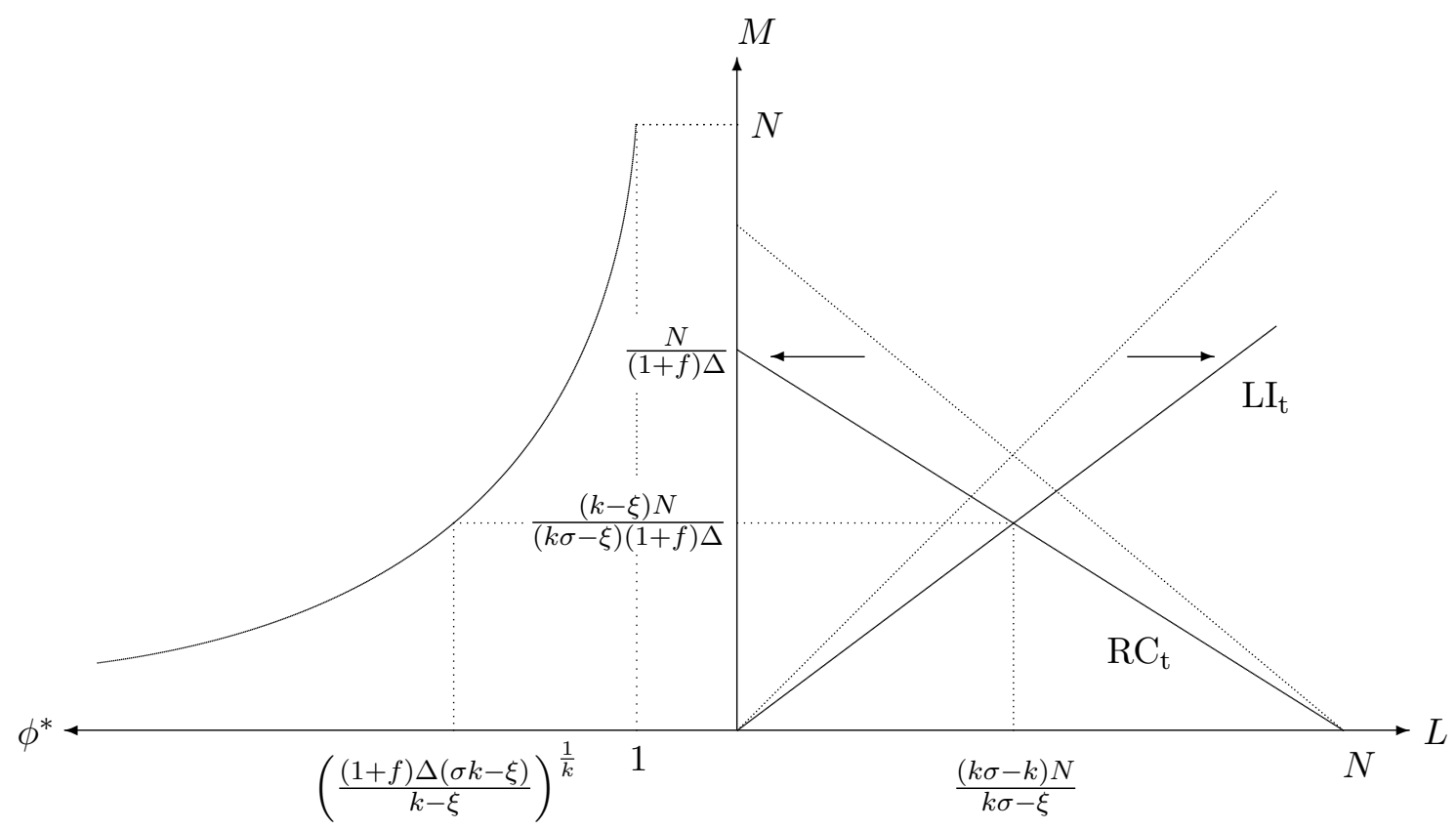

Figure 3: Equilibrium in the open economy

the average firm, $r^{o}(\tilde{\phi})$, as foreign firms with a high productivity level enter the domestic market in the open economy. This would imply both a lower revenue and a lower profit of the marginal firm. In order to restore indifference of the marginal entrepreneur between running the firm and not doing so, the expected wage (proportional to aggregate output per worker) would have to fall as well. For a given level of $Y$ this requires an increase in the number of workers $L$ (by a factor $\Delta$ ).

Together, $\mathrm{LI}_{\mathrm{t}}$ and $\mathrm{RC}_{\mathrm{t}}$ allow us to determine $L$ and $M$, and the resulting value for $M$ can be substituted into eq. (16) to yield the equilibrium cutoff ability $\phi^{*}$. In particular, we get

$$
\begin{aligned}
L & =\frac{k \sigma-k}{k \sigma-\xi} N \\
M & =\frac{k-\xi}{(k \sigma-\xi)(1+f) \Delta} N \\
\phi^{*} & =\left((1+f) \Delta \frac{k \sigma-\xi}{k-\xi}\right)^{1 / k}
\end{aligned}
$$


By comparison to eqs. (17) to (19) we see that the mass of entrepreneurs shrinks after opening up to international trade, and therefore the cutoff ability increases. In contrast, the labour supply stays constant. These effects can be verified by inspection of figure 3 .

\subsection{Welfare and Unemployment}

With the results in section 3.3 at hand, we can now turn to determining welfare and unemployment in the open economy. As under autarky, we use the fair wage constraint of the average firm, which now becomes $w^{o}\left(\tilde{\phi}_{t}\right)=\left(r^{o}\left(\tilde{\phi}_{t}\right) / \sigma\right)^{\theta}(\rho Y / L)^{1-\theta}$. Accounting for $\rho \tilde{\phi}_{t}=w^{o}\left(\tilde{\phi}_{t}\right)$ and repeating the steps in the derivation of eq. (22) we arrive at

$$
\frac{Y}{N}=\left(\frac{\Delta}{1+\chi}\right)^{\frac{1}{\sigma-1}} \Delta^{\frac{1}{k}} \frac{Y_{a}}{N}
$$

where the first term on the right hand side equals $\left(\tilde{\phi}_{t} / \tilde{\phi}\right)^{\frac{\xi}{\sigma-1}}$ and the second term equals $\tilde{\phi} / \tilde{\phi}_{a}$. The employment rate of production workers in the open economy follows from the adding-up condition:

$$
(1-U) L=N\left[\int_{\phi^{*}}^{\phi_{x}^{*}} l^{o}(\phi) g(\phi) d \phi+\left(1+\tau^{1-\sigma}\right) \int_{\phi_{x}^{*}}^{\infty} l^{m}(\phi) g(\phi) d \phi\right] .
$$

Proceeding as in the case of the closed economy we arrive at

$$
1-U=\frac{\Gamma}{\Delta}\left(1-U_{a}\right)
$$

with

$$
\Gamma \equiv 1+\chi^{\frac{k-(1-\theta) \xi}{k}}\left[\left(1+\tau^{1-\sigma}\right)^{\frac{(1-\theta) \xi}{\sigma-1}}-1\right]
$$

We can now compare welfare and unemployment in the autarky equilibrium with the respective values for the open economy. This gives the following result.

Proposition 3. International trade increases the rate of unemployment. Furthermore, the condition $f_{x} \geq 1+f$ is sufficient for a positive welfare effect.

Proof. See Appendix. 
The intuition for these results is as follows. Considering the welfare effect first, we know from the analysis of the autarky case that, all other things equal, per capita income $Y / N$ increases with the average productivity of firms $\tilde{\phi}_{a}$ (see (22)). Furthermore, it has been shown in section 3.3 that international trade renders firm ownership for the least productive entrepreneurs unattractive, implying a decline in $M$ and an increase in the marginal productivity $\phi^{*}$. This induces an increase in the average productivity of domestic firms $\tilde{\phi}$ as defined above. However, as shown above, the average productivity of all firms in the market, which is represented by $\tilde{\phi}_{t}$, can be larger or smaller than $\tilde{\phi}$, depending on the relative strength of the export-selection, lost-in-transit and exporter-wage-premium effects, respectively. With $f_{x} \geq 1+f$ we have $\tilde{\phi}_{t} / \tilde{\phi} \geq 1$. In this case, international trade unambiguously increases the average productivity in the market and therefore per capita income $Y / N$. In contrast, with $f_{x}<1+f$ we have $\tilde{\phi}_{t} / \tilde{\phi}<1$. Hence, while international trade unambiguously increases $\tilde{\phi}$, the average productivity in the market and therefore per capita income may fall if $f_{x} /(1+f)$ is sufficiently small.

To provide an intuition for the unemployment effects of trade liberalisation, it is useful to focus on a parameter constellation with $f_{x}=1+f$, first. From above, we know that per capita income increases in this case. An increase in per capita income, however, is associated with an increase in the demand for final and intermediate goods. All other things equal, this leads to an increase in the demand for labour, thereby reducing equilibrium unemployment. However, the increase in revenues of the most productive firms leads to a higher reference wage of workers in these firms, according to (7), so that the labour demand increase following the opening up to international trade is weakened by the fair wage mechanism described in section 2.3. Furthermore, there is an additional counteracting effect, as the increase in the average productivity level implies that less labour input is needed to produce a given output level. The two latter effects dominate if $f_{x}=1+f$, so that unemployment unambiguously increases in this case. If $f_{x} \neq 1+f$, there are additional implications, because the combined lost-in-transit and exporter-wage-premium effects are not equal in absolute value to the export-selection effect. However, these additional implications do not reverse the aforementioned outcome, so that unemployment 
also increases if $\tilde{\phi}_{t} \neq \tilde{\phi}$.

Finally, it is possible to go beyond the results derived so far, and make some inference about the effects of a marginal reduction in either $\tau$ or $f_{x}$ on welfare and aggregate employment. Proposition 3 provides the natural starting point, as it involves a comparison of the autarky situation, $\chi=0$, with the situation of an arbitrary $\chi \in(0,1)$. It follows then directly that a marginal reduction in either transport cost parameter increases the unemployment rate and - under the additional assumption $f_{x} \geq 1+f$-leads to an increase in welfare as long as $\chi$, the proportion of firms that export, is sufficiently small. However, the effects of a $\tau$ or $f_{x}$ reduction need not be monotonic, i.e. further trade liberalisation can reduce welfare and/or the rate of unemployment for sufficiently low levels of transport cost.

\subsection{Income Distribution}

Similar to the autarky scenario, we use the ratio between the average profit of domestic firms, $\bar{\pi}_{t}=(1+\chi) r^{o}\left(\tilde{\phi}_{t}\right)-\left(f+\chi f_{x}\right)(1-U) \bar{w}$, and the expected labour income of production workers, $(1-U) \bar{w}$, as our measure for inter-group inequality. Furthermore, to determine intra-group inequality of profits and labour income we look at the respective Gini coefficients. Deferring derivation details to the Appendix, we can note that inter-group inequality in the open economy is determined by

$$
\frac{\bar{\pi}_{t}}{(1-U) \bar{w}}=\frac{k+\xi\left(f+\chi f_{x}\right)}{k-\xi}
$$

Furthermore, the Gini coefficient for profit income is given by

$$
A_{M}=\frac{k \xi\left(1+f+\chi f_{x}\right)+(k-\xi) \xi \chi f_{x}(1-\chi)}{(2 k-\xi)\left[k+\xi\left(f+\chi f_{x}\right)\right]},
$$

while the respective coefficient for labour income is given by

$$
\begin{aligned}
& A_{L}=A_{L}^{a}\left[1+\frac{2(k-\xi) \chi f_{x}\left(1-\chi^{1-(1-\theta) \xi / k}\right)}{\left(1+f+\chi f_{x}\right) \theta \xi \Gamma}\right. \\
&\left.-\frac{2[k-(1-\theta) \xi](1+f)(\Gamma-1)\left(1-\chi^{1-\xi / k}\right)}{\left(1+f+\chi f_{x}\right) \theta \xi \Gamma}\right],
\end{aligned}
$$


with $A_{L}^{a}$ denoting the Gini coefficient for labour income in the autarky scenario. As with $\theta=0$ all firms pay the same wage, it is clear that $\lim _{\theta \rightarrow 0} A_{L}=0$ must hold. A comparison of eqs. (24) to (26) and (41) to (43) gives the following result.

Proposition 4. International trade increases inter-group inequality as well as intra-group inequality for both entrepreneurs and workers.

Proof. See Appendix.

For an intuition of the inter-group inequality effect, note first that entrepreneurial income of the marginal producer is linked to the expected (or average) income of production workers, according to indifference condition (6). This implies that an increase in per capita income $Y / N$ (see Proposition 3) translates into a pari passu increase of $(1-U) \bar{w}$ and $\pi^{o}\left(\phi^{*}\right)$. However, there are additional profit gains for the most productive firms, due to exports to the foreign market. As a consequence average profit income including both exporting and non-exporting firms rises disproportionally, thereby inducing an increase in inter-group inequality after the opening up to international trade.

With regard to the impact of trade liberalisation on the Gini coefficient of entrepreneurial income, we have to distinguish two counteracting effects. On the one hand, the exit of the least productive firms reduces, all other things equal, intra-group inequality among entrepreneurs. On the other hand, selection of the most productive firms into export status raises these firms' profits and thus intra-group inequality among entrepreneurs. In our setting, it is the second effect that dominates, so that Gini coefficient $A_{M}$ is unambiguously higher in the open economy. These two sides of the selection effect - exit of the least productive firms and exporting of the most productive ones - are also crucial for an understanding of how opening up to international trade affects the Gini coefficient for labour income, $A_{L}$. On the one hand, because the least productive firms pay the lowest wages, exit of these firms lowers inequality of labour income ceteris paribus. On the other hand, expansion of the most productive firms due to exports to the foreign market raises inequality of labour income, since these firms pay the highest wages. The latter effect is reinforced by the fair-wage mechanism in (7), as access to the foreign market stimulates 
operating profits and, thereby, induces an increase in the reference wage of workers in exporting firms. ${ }^{18}$

In analogy to the previous section, we can use the results in Proposition 4 to get some insight into the effects of marginal trade liberalisation on income inequality. In particular, using the same reasoning as in section 3.4, we can infer that marginal reductions in $\tau$ or $f_{x}$ increase all three measures of income inequality for sufficiently low values of $\chi$. It is furthermore possible to show that both types of trade liberalisation exhibit a monotonic impact on inter-group inequality as long as there is selection of the best firms into export status, i.e. $\chi<1$. On the other hand the impact of trade cost changes on the two Gini coefficients turns out to be non-monotonic in general.

\section{Conclusion}

The key objective of this paper is to present an analytically tractable theoretical framework that allows us to account for the empirical fact that the recent wave of globalisation with a surge in international outsourcing activities has been accompanied by a surge in both inter- and intra-group inequality. For this purpose, we build a model in which there is income inequality between as well as within two key groups of individuals in the economy: the group of entrepreneurs and the group of production workers. There is self-selection of individuals into these two groups, and the group of production workers consists of individuals whose entrepreneurial ability is too low to make it worthwhile for them to run a firm. While firms run by more able entrepreneurs make higher profits, the entrepreneurial ability of production workers has no bearing on their respective job performance. Still, wages are differentiated within the group of production workers because there is rent

\footnotetext{
${ }^{18}$ When analysing the inequality effects, we have also shown that a movement from autarky to trade shifts the Lorenz curve for profit and labour income downwards in the respective Lorenz curve diagrams. This implies that, even according the relatively strict criterion of Lorenz dominance, both labour and entrepreneurial income are less even distributed in the open economy. However, in the interest brevity, we have deferred a rigorous analysis of the Lorenz curve effects to a supplement, which is available from the authors upon request.
} 
sharing at the firm level due to fairness preferences of workers, leading to higher wages for employees in firms with higher operating profits.

Comparing the autarky scenario with the open economy case, we find that while, subject to only mild restrictions, per capita income increases and hence there are typically aggregate gains from trade, not all individuals participate in these gains to an equal extent. For one, trade liberalisation increases unemployment among production workers, and those workers who lose their job are definitely worse off in the open economy. Furthermore, average inequality between the group of entrepreneurs and the group of workers increases, because entrepreneurs gain disproportionately. Even within these groups there are notable differences in the gains from trade liberalisation: the most able entrepreneurs see their incomes soar, and this effect is instrumental to an increase of income inequality within the group of entrepreneurs. The income distribution of employed production workers becomes more unequal as well, as the employees in the high-productivity firms participate in the economic success of their employers.

\section{Appendix}

\section{Proof of Proposition 1}

Let us first consider the impact of $\theta$ on $Y / N$. According to (13), (19) and (22), we get

$$
\frac{Y}{N}=\left(\frac{k \sigma-k}{k \sigma-\xi}\right)\left(\frac{k-\xi}{k(1+f)}\right)^{\theta}\left(\frac{(k \sigma-\xi)(1+f)}{k-\xi}\right)^{1 / k}\left(\frac{k}{k-\xi}\right)^{1 / \xi}
$$

Differentiating with respect to $\theta$ (and noting $d \xi / d \theta=-\xi^{2}$ ), we obtain

$$
\frac{d(Y / N)}{d \theta}=\frac{Y}{N}\left[-\ln (1+f)-\frac{k-1}{k} \frac{\xi^{2}}{k \sigma-\xi}-\left(\frac{1}{\sigma-1}+\frac{1}{k}\right) \frac{\xi^{2}}{k-\xi}\right]<0 .
$$

Second, differentiating (23) with respect to $\theta$ gives

$$
\frac{d(1-U)}{d \theta}=(1-U)\left[-\ln (1+f)+\frac{\xi[\theta k \xi-(k-\xi)]}{(k-\xi)[k-(1-\theta) \xi]}\right] .
$$

Noting $k-\xi>\theta k \xi \Longleftrightarrow k>\sigma-1$, the term in brackets is strictly negative, and hence we have $d(1-U) / d \theta<0$. This completes the proof. QED. 


\section{Derivation of the Gini Coefficient in (25)}

A first ingredient we need to determine the Gini coefficient for entrepreneurial income is $\Pi(\bar{\phi}) / \bar{\Pi}$, which gives the ratio of cumulative profits for all firms with a productivity level lower than or equal to $\bar{\phi} \in\left[\phi^{*}, \infty\right]$ and aggregate profits $\bar{\Pi}$. We can calculate this ratio in the following way:

$$
\frac{\Pi(\bar{\phi})}{\bar{\Pi}}=\frac{M}{\left(1-G\left(\phi^{*}\right)\right) \bar{\Pi}} \int_{\phi^{*}}^{\bar{\phi}} \pi(\phi) g(\phi) d \phi
$$

Now, define $\gamma \equiv 1-\left(\bar{\phi} / \phi^{*}\right)^{-k}$, where $\gamma$ is the proportion of all firms with a productivity smaller than or equal to $\bar{\phi}$. This allows us to rewrite the above as

$$
Q_{M}(\gamma) \equiv \frac{k(1+f)}{k+\xi f}\left[1-(1-\gamma)^{1-\xi / k}\right]-\frac{(k-\xi) f \gamma}{k+\xi f}
$$

which represents the Lorenz curve. Note that $Q_{M}(0)=0, Q_{M}(1)=1$ and $Q_{M}^{\prime}(\gamma)>0$. The Gini coefficient in (25) then follows from $A_{M}=1-2 \int_{0}^{1} Q_{M}(\gamma) d \gamma$. QED.

\section{Derivation of the Gini Coefficient in (26)}

Aggregate labour income in the economy is given by $\bar{W}=\rho Y$. As before, we now derive aggregate labour income of workers employed in firms with productivities up to $\bar{\phi}$ as a proportion of overall labour income:

$$
\frac{W(\bar{\phi})}{\bar{W}}=\frac{M}{\left(1-G\left(\phi^{*}\right)\right) \bar{W}} \int_{\phi^{*}}^{\bar{\phi}} w(\phi) l(\phi) g(\phi) d \phi
$$

Substituting $w(\phi) l(\phi)=\rho r(\phi)$, this can be rewritten to give

$$
\frac{W(\bar{\phi})}{\bar{W}}=1-\left(\frac{\bar{\phi}}{\phi^{*}}\right)^{\xi-k} \text {. }
$$

We define $\gamma$ as the proportion of workers employed in firms with productivities lower than or equal to $\bar{\phi}$, resulting in $\gamma \equiv 1-\left(\bar{\phi} / \phi^{*}\right)^{(1-\theta) \xi-k}$. Substituting for $\bar{\phi} / \phi^{*}$, we arrive at the following expression for the Lorenz curve:

$$
Q_{L}(\gamma)=1-(1-\gamma)^{\frac{k-\xi}{k-\xi+\theta \xi}}
$$

The Gini coefficient in (26) follows from $A_{L}=1-2 \int_{0}^{1} Q_{L}(\gamma) d \gamma$. QED. 


\section{Proof of Proposition 2}

Consider $d \xi / d \theta=-\xi^{2}<0$. Then, noting $\omega^{\prime}(\xi)=k(1+f) /(k-\xi)^{2}$, according to (24), implies $\omega^{\prime}(\xi) \times d \xi / d \theta<0$. Furthermore, rearranging terms in $(25)$ gives $A_{M}=k(1+$ $f) /[(k / \xi+f)(2 k-\xi)]$, so that $d A_{M} / d \xi>0$ and thus $d A_{M} / d \theta<0$ is immediate. Let us now rearrange terms in (26), to obtain $A_{L}=1 /[2 g(\theta)+1]$, with $g(\theta) \equiv k /(\theta \xi)-1 / \theta$. Substituting $\theta \xi=\theta(\sigma-1) /[1+\theta(\sigma-1)]$, further gives $g(\theta)=[k-(\sigma-1)] /[\theta(\sigma-1)]+k$, with $g^{\prime}(\theta)>,=,<0$ if $\sigma-1>,=,<k$. This implies that $k>\sigma-1$ is necessary and sufficient for $d A_{L} / d \theta>0$, which completes the proof. $Q E D$.

\section{Derivation of the Relationship between $\tilde{\phi}$ and $\tilde{\phi}_{t}$ in (31)}

The CES price index in the open economy is given by

$$
\begin{array}{r}
P^{1-\sigma}=M_{t}^{-1}\left[N\left(\int_{\phi^{*}}^{\phi_{x}^{*}} p^{o}(\phi)^{1-\sigma} g(\phi) d \phi+\int_{\phi_{x}^{*}}^{\infty} p^{m}(\phi)^{1-\sigma} g(\phi) d \phi\right)\right. \\
\left.+N \int_{\phi_{x}^{*}}^{\infty} \tau^{1-\sigma} p^{m}(\phi)^{1-\sigma} g(\phi) d \phi\right] .
\end{array}
$$

Using $P=1, N\left(\phi^{*}\right)^{-k}=M$ and $M_{t}=(1+\chi)\left(1-G\left(\phi^{*}\right)\right) N$, this can be rewritten as

$$
1=\frac{\left(\phi^{*}\right)^{k}}{(1+\chi)}\left[\int_{\phi^{*}}^{\phi_{x}^{*}} p^{o}(\phi)^{1-\sigma} g(\phi) d \phi+\left(1+\tau^{1-\sigma}\right) \int_{\phi_{x}^{*}}^{\infty} p^{m}(\phi)^{1-\sigma} g(\phi) d \phi\right] .
$$

Noting that $\left(1+\tau^{1-\sigma}\right)\left[p^{m}(\phi) / p^{o}(\phi)\right]^{1-\sigma}=\left(1+\tau^{1-\sigma}\right) r^{m}(\phi) / r^{o}(\phi)=\left(1+\tau^{1-\sigma}\right)^{\xi /(\sigma-1)}$, according to (4), (5) and (28), and accounting for $p^{o}(\phi) / p^{o}(\tilde{\phi})=(\phi / \tilde{\phi})^{-\xi /(\sigma-1)}$, according to (10), we obtain from tedious but straightforward calculations

$$
1=\frac{k}{k-\xi}\left(\frac{\phi^{*}}{\tilde{\phi}}\right)^{\xi} \frac{p^{o}(\tilde{\phi})^{1-\sigma}}{1+\chi}\left[1-\left(\frac{\phi_{x}^{*}}{\phi^{*}}\right)^{\xi-k}+\left(1+\tau^{1-\sigma}\right)^{\xi /(\sigma-1)}\left(\frac{\phi_{x}^{*}}{\phi^{*}}\right)^{\xi-k}\right] .
$$

Furthermore, substituting $\left(\phi_{x}^{*} / \phi^{*}\right)^{-k}=\chi$ and $\left(\phi^{*} / \tilde{\phi}\right)^{\xi}=(k-\xi) / k$ gives

$$
1=\left(\frac{\tilde{\phi}}{\tilde{\phi}_{t}}\right)^{\xi} \frac{p^{o}\left(\tilde{\phi}_{t}\right)^{1-\sigma}}{1+\chi}\left\{1+\chi\left[\left(1+\tau^{1-\sigma}\right)^{\xi /(\sigma-1)}-1\right]\left(\frac{\phi_{x}^{*}}{\phi^{*}}\right)^{\xi}\right\}
$$

Finally, defining $\tilde{\phi}_{t}$ in a way to ensure $p^{o}\left(\tilde{\phi}_{t}\right)=1$, which is equivalent to $q^{o}\left(\tilde{\phi}_{t}\right)=Y / M_{t}$, and solving for the productivity average, we arrive at

$$
\tilde{\phi}_{t}=\tilde{\phi}\left\{\frac{1}{1+\chi}\left[1+\chi\left(\left(1+\tau^{1-\sigma}\right)^{\xi /(\sigma-1)}-1\right)\left(\frac{\phi_{x}^{*}}{\phi^{*}}\right)^{\xi}\right]\right\}^{1 / \xi}
$$


which, by virtue of (30), can be reformulated to (31).

\section{Proof of Proposition 3}

Let us first consider the employment effects. Substituting $(1+\chi)\left(\tilde{\phi}_{t} / \tilde{\phi}\right)^{\xi}=1+\chi f_{x} /(1+f)$, according to (31), it follows from eqs. (39) and (40) that

$$
U>U^{a} \Longleftrightarrow\left[\left(1+\tau^{1-\sigma}\right)^{\frac{(1-\theta) \xi}{\sigma-1}}-1\right] \chi^{-(1-\theta) \xi / k}<\frac{f_{x}}{1+f} .
$$

As $\left(1+\tau^{1-\sigma}\right)>1$ and $\chi<1$, the following inequality holds:

$$
\left[\left(1+\tau^{1-\sigma}\right)^{\frac{(1-\theta) \xi}{\sigma-1}}-1\right] \chi^{-(1-\theta) \xi / k}<\left[\left(1+\tau^{1-\sigma}\right)^{\frac{\xi}{\sigma-1}}-1\right] \chi^{-\xi / k}
$$

and the right-hand side expression equals $f_{x} /(1+f)$, according to (30).

Let us now turn to the welfare effects. Accounting for $\Delta=\left(1+f+\chi f_{x}\right) /(1+f)$, it follows from eq. (38) that

$$
\frac{Y / N}{Y^{a} / N}=\left[\frac{\left[1+\chi f_{x} /(1+f)\right]^{1+(\sigma-1) / k}}{1+\chi}\right]^{1 /(\sigma-1)} .
$$

Hence, $f_{x} \geq 1+f$ is sufficient for $(Y / N) /\left(Y^{a} / N\right)>1$. This completes the proof. QED.

\section{Derivation of Inter-Group Inequality in (41)}

To determine inter-group inequality in the open economy, note first that aggregate profits can be written in the following way: $\bar{\Pi}_{t}=M\left[(1+\chi) r^{o}\left(\tilde{\phi}_{t}\right) / \sigma-\left(f+\chi f_{x}\right)(1-U) \bar{w}\right]$. Substituting into $\bar{\pi}_{t}=\bar{\Pi}_{t} / M$ and accounting for $(1+\chi) r^{o}\left(\tilde{\phi}_{t}\right)=\left[1+\chi f_{x} /(1+f)\right] r^{o}(\tilde{\phi})$, gives $\bar{\pi}_{t}=\left(1+f+\chi f_{x}\right) r^{o}(\tilde{\phi}) /[\sigma(1+f)]-\left(f+\chi f_{x}\right)(1-U) \bar{w}$. Dividing $\bar{\pi}_{t}$ by $(1-U) \bar{w}$ and accounting for $(1-U) \bar{w}=r^{o}\left(\phi^{*}\right) /[\sigma(1+f)]$, we further obtain $\bar{\pi}_{t} /[(1-U) \bar{w}]=$ $\left(1+f+\chi f_{x}\right) r^{o}(\tilde{\phi}) / r^{o}\left(\phi^{*}\right)-\left(f+\chi f_{x}\right)$. Substituting $r^{o}(\tilde{\phi}) / r^{o}\left(\phi^{*}\right)=k /(k-\xi)$ and rearranging terms, finally gives (41). QED.

\section{Derivation of the Gini Coefficient in (42)}

The derivation of the Gini coefficient in the open economy is similar to the respective derivation under autarky, with the mere difference that we have to distinguish between 
exporters and non-exporters if trade is possible. The ratio of cumulative profits for all non-exporters with a productivity level lower than or equal to $\bar{\phi} \in\left[\phi^{*}, \phi_{x}^{*}\right)$ and aggregate profits $\bar{\Pi}_{t}$ is given by

$$
\frac{\Pi(\bar{\phi})}{\bar{\Pi}_{t}}=\frac{M}{\left(1-G\left(\phi^{*}\right)\right) \bar{\Pi}_{t}} \int_{\phi^{*}}^{\bar{\phi}} \pi^{o}(\phi) g(\phi) d \phi
$$

Similar to the autarky scenario, we can now define $\gamma \equiv 1-\left(\bar{\phi} / \phi^{*}\right)^{-k}$ and rewrite the latter ratio in the following way:

$$
Q_{M}^{1}(\gamma) \equiv \frac{k(1+f)}{k+\xi\left(f+\chi f_{x}\right)}\left[1-(1-\gamma)^{1-\xi / k}\right]-\frac{k-\xi f \gamma}{k+\xi\left(f+\chi f_{x}\right)}
$$

Note that $Q_{M}^{1}$ represents the first segment of the Lorenz curve, which is relevant if $\gamma \in$ $\left[0, b_{M}\right)$, with $b_{M} \equiv 1-\left(\phi_{x}^{*} / \phi^{*}\right)^{-k}=1-\chi$. Evaluating $Q_{M}^{1}$ at $\gamma=b_{M}^{1}$ gives

$$
Q_{M}^{1}\left(b_{M}\right)=\frac{k(1+f)}{k+\xi\left(f+\chi f_{x}\right)}\left[1-\chi^{1-\xi / k}\right]-\frac{k-\xi f(1-\chi)}{k+\xi\left(f+\chi f_{x}\right)} .
$$

The ratio of cumulative profits for all firms (exporters and non-exporters) with a productivity level up to $\bar{\phi} \in\left[\phi_{x}^{*}, \infty\right)$ and aggregate profits $\bar{\Pi}_{t}$ is given by

$$
\frac{\Pi(\bar{\phi})}{\bar{\Pi}_{t}}=Q_{M}^{1}\left(b_{M}\right)+\frac{M}{\left(1-G\left(\phi^{*}\right)\right) \bar{\Pi}_{t}} \int_{\phi^{*}}^{\bar{\phi}} \pi^{m}(\phi) g(\phi) d \phi,
$$

Hence, the second segment of the Lorenz curve is given by

$$
\begin{aligned}
Q_{M}^{2}(\gamma) \equiv Q_{M}^{1}\left(b_{M}\right)+\frac{k(1+f)\left(1+\tau^{1-\sigma}\right)^{1-\theta \xi}}{k+\xi\left(f+\chi f_{x}\right)}\left[\chi^{1-\xi / k}-(1-\gamma)^{1-\xi / k}\right] & \\
- & \frac{(k-\xi)\left(f+f_{x}\right)\left(\gamma-b_{M}\right)}{k+\xi\left(f+\chi f_{x}\right)}
\end{aligned}
$$

Note that $Q_{M}^{1}\left(b_{M}\right)=Q_{M}^{2}\left(b_{M}\right)$. Putting the two segments together, the Lorenz curve in the open economy is given by

$$
Q_{M}^{t}(\gamma) \equiv\left\{\begin{array}{ll}
Q_{M}^{1}(\gamma) & \text { if } \gamma \in\left[0, b_{M}\right) \\
Q_{M}^{2}(\gamma) & \text { if } \gamma \in\left[b_{M}, 1\right]
\end{array},\right.
$$

where $Q_{M}^{t}(0)=0, Q_{M}^{t}(1)=1$ and $d Q_{M}^{t}(\gamma) / d \gamma>0$. The Gini coefficient in (42) then follows from $A_{M}=1-2 \int_{0}^{1} Q_{M}^{t}(\gamma) d \gamma$. QED. 


\section{Derivation of the Gini Coefficient in (43)}

In the open economy, we have to distinguish between workers employed in non-exporting and those employed in exporting firms. Let us first determine the ratio between aggregate labour income of workers employed in firms with productivity levels up to $\bar{\phi} \in\left[\phi^{*}, \phi_{x}^{*}\right)$ and aggregate labour income $\bar{W}=\rho Y$. This ratio is given by

$$
\frac{W(\bar{\phi})}{\bar{W}}=\frac{M}{\left(1-G\left(\phi^{*}\right)\right) \bar{W}} \int_{\phi^{*}}^{\bar{\phi}} w^{o}(\phi) l^{o}(\phi) g(\phi) d \phi .
$$

Substituting $w^{o}(\phi) l^{o}(\phi)=\rho r^{o}(\phi)$, the latter can be rewritten to give

$$
\frac{W(\bar{\phi})}{\bar{W}}=\frac{1+f}{1+f+\chi f_{x}}\left[1-\left(\frac{\bar{\phi}}{\phi^{*}}\right)^{\xi-k}\right] .
$$

We now define $\gamma$ as the proportion of workers employed in firms with productivities lower than or equal to $\bar{\phi}$, resulting in $\gamma \equiv\left[1-\left(\bar{\phi} / \phi^{*}\right)^{(1-\theta \xi-k)}\right] / \Gamma$ if $\bar{\phi}<\phi_{x}^{*}$. Note that the $\gamma-\phi$ relationship determined by the latter expression differs from the respective relationship in the closed economy, as the most-productive firms now have access to a foreign market and therefore increase their employment share. Substituting for $\bar{\phi} / \phi^{*}$, we obtain the following expression for the first segment of the Lorenz curve:

$$
Q_{L}^{1}(\gamma)=\frac{1+f}{1+f+\chi f_{x}}\left[1-(1-\Gamma \gamma)^{\frac{k-\xi}{k-(1-\theta) \xi}}\right]
$$

Note that $Q_{L}^{1}(\gamma)$ is the relevant segment, if $\gamma \in\left[0, b_{L}\right)$, with $b_{L} \equiv\left[1-\left(\phi_{x}^{*} / \phi^{*}\right)^{(1-\theta) \xi-k}\right] / \Gamma=$ $\left[1-\chi^{1-(1-\theta) \xi / k}\right] / \Gamma$. Evaluating $Q_{L}^{1}(\gamma)$ at $b_{L}$ gives

$$
Q_{L}^{1}\left(b_{L}\right)=\frac{1+f}{1+f+\chi f_{x}}\left(1-\chi^{1-\xi / k}\right) .
$$

To determine the ratio between aggregate labour income of workers employed in firms with productivity levels up to $\bar{\phi} \in\left[\phi_{x}^{*}, \infty\right]$ and aggregate labour income $\bar{W}=\rho Y$, we look at

$$
\frac{W(\bar{\phi})}{\bar{W}}=Q_{L}^{1}\left(b_{L}\right)+\frac{M\left(1+\tau^{1-\sigma}\right)}{\left(1-G\left(\phi^{*}\right)\right) \bar{W}} \int_{\phi_{x}^{*}}^{\bar{\phi}} w^{m}(\phi) l^{m}(\phi) g(\phi) d(\phi) .
$$

Substituting $w^{m}(\phi) l^{m}(\phi)=\rho r^{m}(\phi)$, this can be rewritten to give

$$
\frac{W(\bar{\phi})}{\bar{W}}=Q_{L}^{1}\left(b_{L}\right)+\frac{(1+f)\left(1+\tau^{1-\sigma}\right)^{1-\theta \xi}}{1+f+\chi f_{x}}\left[\chi^{1-\xi / k}-\left(\frac{\bar{\phi}}{\phi^{*}}\right)^{\xi-k}\right] .
$$


With $\gamma$ being defined as the proportion of workers employed in firms with productivities lower than or equal to $\bar{\phi}$, we have $\gamma \equiv 1-\left(1+\tau^{1-\sigma}\right)^{(1-\theta) \xi /(\sigma-1)}\left(\bar{\phi} / \phi^{*}\right)^{(1-\theta \xi-k)} / \Gamma$ if $\bar{\phi} \geq \phi_{x}^{*}$. Substituting for $\bar{\phi} / \phi^{*}$ and considering $Q_{L}^{1}\left(b_{L}\right)$ from above, we arrive at the following expression for the second segment of the Lorenz curve:

$$
Q_{L}^{2}(\gamma)=1-\frac{(1+f)\left(1+\tau^{1-\sigma}\right)^{1-\theta \xi}}{1+f+\chi f_{x}}\left[\frac{(1-\gamma) \Gamma}{\left(1+\tau^{1-\sigma}\right)^{(1-\theta) \xi /(\sigma-1)}}\right]^{\frac{k-\xi}{k-(1-\theta) \xi}}
$$

Note that $Q_{L}^{1}\left(b_{L}\right)=Q_{L}^{2}\left(b_{L}\right)$. Putting together the Lorenz curve for labour income in the open economy is given by

$$
Q_{L}^{t}(\gamma) \equiv \begin{cases}Q_{L}^{1} & \text { if } \gamma \in\left[0, b_{L}\right) \\ Q_{L}^{2} & \text { if } \gamma \in\left[b_{L}, 1\right]\end{cases}
$$

$Q_{L}^{t}$ has the usual properties: $Q_{L}^{t}(0)=0, Q_{L}^{t}(1)=1$ and $d Q_{L}^{t}(\gamma) / d \gamma>0$. The Gini coefficient in (43) follows from $1-2 \int_{0}^{1} Q_{L}^{t}(\gamma) d \gamma$. QED.

\section{Proof of Proposition 4}

Denoting autarky equilibrium variables by superscript $a$, it follows from (24) and (41) that

$$
\frac{\bar{\pi}_{t} /[(1-U) \bar{w}]}{\bar{\pi}^{a} /\left[\left(1-U^{a}\right) \bar{w}^{a}\right]}=1+\frac{\chi f_{x}}{k+\xi f} .
$$

Hence, inter-group inequality is higher in the open economy. Furthermore, comparing eqs. (25) and (42) we can conclude that

$$
A_{M}^{a}>,=,<A_{M} \quad \Longleftrightarrow 0>,=,<\xi(k-\xi) \chi f_{x}[2 k+\xi f-\chi(k+\xi f)] .
$$

Noting that $2 k+\xi f>\chi(k+\xi f)$ holds for any $\chi \in[0,1]$, this implies $A_{M}^{a}<A_{M}$ and thus a higher inequality of entrepreneurial income in the open economy.

Finally, it follows from eqs. (26) and (43) that $A_{L}>,=,<A_{L}^{a}$ if

$$
(k-\xi) \chi f_{x}\left(1-\chi^{1-(1-\theta) \xi / k}\right)>,=,<[k-(1-\theta) \xi](1+f)(\Gamma-1)\left(1-\chi^{1-\xi / k}\right) .
$$

Substituting $f_{x}=\left[\left(1+\tau^{1-\sigma}\right)^{\xi /(\sigma-1)}-1\right](1+f) \chi^{-\xi / k}$ from $(30)$ and $\Gamma-1=[(1+$ $\left.\left.\tau^{1-\sigma}\right)^{(1-\theta) \xi /(\sigma-1)}-1\right] \chi^{1-(1-\theta) \xi / k}$ from $(40)$, we can further conclude that $A_{L}>,=,<0$ 
if $\chi^{1-\xi / k}(1+f) \Omega(\chi)>,=,<0$, where

$$
\begin{aligned}
\Omega(\chi) \equiv(k-\xi)[ & \left.\left(1+\tau^{1-\sigma}\right)^{\xi /(\sigma)}-1\right]\left(1-\chi^{1-(1-\theta) \xi / k}\right) \\
& -\chi^{\theta \xi / k}[k-(1-\theta) \xi]\left[\left(1+\tau^{1-\sigma}\right)^{(1-\theta) \xi /(\sigma-1)}-1\right]\left(1-\chi^{1-\xi / k}\right) .
\end{aligned}
$$

Noting $\Omega^{\prime}(\chi)<0$ and $\Omega(1)=0$, we obtain $\Omega(\chi)>0$ and thus $A_{L}>A_{L}^{a}$ for any $\chi \in(0,1)$.

This completes the proof of Proposition 4 . QED.

\section{References}

Akerlof, G.A., Yellen, J.L. (1990). The Fair Wage-Effort Hypothesis and Unemployment, Quarterly Journal of Economics 105, 255-283.

Autor, D.H., Katz, L.F., Kearney, M.F. (2008). Trends in U.S. Wage Inequality: Revising the Revisionists, Review of Economics and Statistics 90, 300-323.

Barth, E., Lucifora, C. (2006). Wage Dispersion, Markets and Institutions: The Effects of the Boom in Education on the Wage Structure, IZA Discussion Paper 2181.

Bayard,K., Troske, K.R. (1999). Examining the Employer-Size Wage Premium in the Manufacturing, Retail Trade, and Service Industries Using Employer-Employee Matched Data, American Economic Review 89, 99-103.

Bernard, A.B., Eaton, J., Jensen, J.B., Kortum, S. (2003). Plants and Productivity in International Trade, American Economic Review 93, 1268-1290.

Bernard, A.B., Jensen, J.B. (1995). Exporters, Jobs, and Wages in U.S. Manufacturing: 1976-1987, Brookings Papers on Economic Activity. Microeconomics, 67-119.

Bernard, A.B., Jensen, J.B. (1999). Exceptional Exporter Performance: Cause, Effect, or Both?, Journal of International Economics 47, 1-25.

Bernard, A.B., Redding, S.J., Schott, P.K. (2007). Comparative Advantage and Heterogeneous Firms, Review of Economic Studies 74, 31-66. 
Bewley, T. (2005). Fairness, Reciprocity, and Wage Rigidity, in: Gintis, H., Bowles, S., Boyd, R., Fehr, E. (Eds.), Moral Sentiments and Material Interests: The Foundations of Cooperation in Economic Life. Cambridge/Mass., MIT Press, 303-338.

Blanchflower, D.G., Oswald, A.J., Sanfey, P. (1996). Wages, Profits, and Rent-Sharing, Quarterly Journal of Economics 111, 227-251.

Clerides, S.K., Lach, S., Tybout, J.R. (1998). Is Learning by Exporting Important? MicroDynamic Evidence from Colombia, Mexico, and Morocco, Quarterly Journal of Economics 113, 903-947.

Danthine, J.P., Kurmann, A. (2006). Efficiency Wages Revisited: The Internal Reference Perspective, Economics Letters 90, 278-284.

Davidson, C., Matusz, S.J., Shevchenko, A. (2008). Globalization and Firm Level Adjustment with Imperfect Labor Markets, Journal of International Economics, forthcoming.

Davis, D., Harrigan, J. (2007). Good Jobs, Bad Jobs, and Trade Liberalization, NBER Working Paper 13139.

Del Gatto, M., Mion, G., Ottaviano, G.I.P. (2006). Trade Integration, Firm Selection and the Costs of Non-Europe, CEPR Discussion Paper $\mathbf{5 7 3 0 .}$

Egger, H., Kreickemeier, U. (2007). Firm Heterogeneity and the Labour Market Effects of Trade Liberalisation. International Economic Review, forthcoming.

Ethier, W.J. (1982). National and International Returns to Scale in the Modern Theory of International Trade, American Economic Review 72, 389-405.

Faggio, G., Salvanes, K., Van Reenen, J. (2007). The Evolution of Inequality in Productivity and Wages: Panel Data Evidence, NBER Working Paper 13351.

Feenstra, R.C., Hanson, G.H. (1996). Globalization, Outsourcing and Wage Inequality, American Economic Review 86, 240-245. 
Feenstra, R.C., Hanson, G.H. (1999). The Impact of Outsourcing and High-technology Capital on Wages: Estimates for the United States, 1979-1990, Quarterly Journal of Economics 114, 907-940.

Fehr, E., Falk, A. (1999). Wage Rigidity in a Competitive Incomplete Contract Market, Journal of Political Economy 107, 106-134.

Fehr, E., Gächter, S. (2000). Fairness and Retaliation: The Economics of Reciprocity, Journal of Economic Perspectives 14, 159-181.

Felbermayr, G., Prat, J., Schmerer, H.J. (2007). Globalization and Labor Market Outcomes: Wage Bargaining, Search Frictions, and Firm Heterogeneity, mimeo, University of Tuebingen.

Geishecker, I., Görg, H. (2008). Winners and Losers: A Micro-level Analysis of International Outsourcing and Wages, Canadian Journal of Economics 41, 243-270.

Ghironi, F., Melitz, M.J. (2005). International Trade and Macroeconomic Dynamics with Heterogeneous Firms, Quarterly Journal of Economics 120, 865-915.

Helpman, E., Itskhoki, O. (2007). Labor Market Rigidities, Trade and Unemployment, NBER Working Paper 13365.

Helpman, E., Melitz, M.J., Yeaple, S.R. (2004). Export Versus FDI with Heterogeneous Firms, American Economic Review 94, 300-316.

Howitt, P. (2002). Looking Inside the Labor Market: A Review Article, Journal of Economic Literature 40, 125-138.

Katz, L.F., Autor, D.H. (1999). Changes in the Wage Structure and Earnings Inequality, in: Ashenfelter, O., Card, D. (eds.), Handbook of Labor Economics, Vol. 3A. Amsterdam, Elsevier, 1463-1555.

Kreickemeier, U., Nelson, D. (2006). Fair Wages, Unemployment and Technological Change in a Global Economy, Journal of International Economics 70, 451-469. 
Manasse, P., Turrini, A. (2001). Trade, Wages, and 'Superstars'. Journal of International Economics 54, 97-117.

Meckl, J., Weigert, B. (2007). Aggregate Productivity, Human-capital Investments and Trade, mimeo, University of Giessen.

Melitz, M.J. (2003). The Impact of Trade on Intra-Industry Reallocations and Aggregate Industry Productivity, Econometrica 71, 1695-1725.

Melitz, M.J., Ottaviano, G.I.P. (2008). Market Size, Trade, and Productivity, Review of Economic Studies 75, 295-316.

Schank, T., Schnabel, C., Wagner, J. (2007). Do Exporters Really Pay Higher Wages? First Evidence from German Linked Employer-Employee Data, Journal of International Economics 72, 52-74.

Shapiro, C., Stiglitz, J.E. (1984). Equilibrium Unemployment as a Worker Discipline Device, American Economic Review 74, 433-444.

Yeaple, S.R. (2005). A Simple Model of Firm Heterogeneity, International Trade, and Wages, Journal of International Economics 65, 1-20. 


\section{CESifo Working Paper Series}

for full list see www.cesifo-group.org/wp

(address: Poschingerstr. 5, 81679 Munich, Germany, office@cesifo.de)

2281 Katrin Assenmacher-Wesche and M. Hashem Pesaran, A VECX* Model of the Swiss Economy, April 2008

2282 Christophe Rault, Robert Sova and Ana Maria Sova, Modeling International Trade Flows between CEEC and OECD Countries, April 2008

2283 Timo Boppart, Josef Falkinger, Volker Grossmann, Ulrich Woitek and Gabriela Wüthrich, Qualifying Religion: The Role of Plural Identities for Educational Production, April 2008

2284 Armin Falk, David Huffman and W. Bentley MacLeod, Institutions and Contract Enforcement, April 2008

2285 Axel Dreher and Stefan Voigt, Does Membership in International Organizations Increase Governments' Credibility? Testing the Effects of Delegating Powers, April 2008

2286 Xavier Freixas and Bruno M. Parigi, Lender of Last Resort and Bank Closure Policy, April 2008

2287 Regina Dionisius, Samuel Muehlemann, Harald Pfeifer, Günter Walden, Felix Wenzelmann and Stefan C. Wolter, Cost and Benefit of Apprenticeship Training - A Comparison of Germany and Switzerland, April 2008

2288 Francesco Daveri and Cecilia Jona-Lasinio, Off-Shoring and Productivity Growth in the Italian Manufacturing Industries, April 2008

2289 Mikael Priks, Do Surveillance Cameras Affect Unruly Behavior? A Close Look at Grandstands, April 2008

2290 Marianna Belloc and Daniela Federici, A Two-Country NATREX Model for the Euro/Dollar, April 2008

2291 Nicolas Treich, The Value of a Statistical Life under Ambiguity Aversion, April 2008

2292 J. Atsu Amegashie, Socially-Tolerable Discrimination, April 2008

2293 M. Hashem Pesaran and Andreas Pick, Forecasting Random Walks Under Drift Instability, April 2008

2294 Steven Brakman, Gus Garita, Harry Garretsen and Charles van Marrewijk, Unlocking the Value of Cross-Border Mergers and Acquisitions, May 2008

2295 Eric O’N. Fisher and Kathryn G. Marshall, The Structure of the American Economy, May 2008 
2296 Claudia M. Buch and Martin Schlotter, Regional Origins of Employment Volatility: Evidence from German States, May 2008

2297 Helmuth Cremer, Philippe De Donder, Dario Maldonado and Pierre Pestieau, Taxing Sin Goods and Subsidizing Health Care, May 2008

2298 Reinhilde Veugelers and Frederick van der Ploeg, Reforming European Universities: Scope for an Evidence-Based Process, May 2008

2299 Jon H. Fiva and Lars J. Kirkebøen, Does the Housing Market React to New Information on School Quality?, May 2008

2300 Tina Klautke and Alfons J. Weichenrieder, Interest Income Tax Evasion, the EU Savings Directive, and Capital Market Effects, May 2008

2301 Harald Badinger and Peter Egger, GM Estimation of Higher Order Spatial Autoregressive Processes in Panel Data Error Component Models, May 2008

2302 Jan K. Brueckner, Slot-Based Approaches to Airport Congestion Management, May 2008

2303 Sören Blomquist, Vidar Christiansen and Luca Micheletto, Public Provision of Private Goods and Nondistortionary Marginal Tax Rates, May 2008

2304 Dan Anderberg and Alessandro Balestrino, The Political Economy of Post-Compulsory Education Policy with Endogenous Credit Constraints, May 2008

2305 Tomer Blumkin, Yoram Margalioth and Efraim Sadka, The Role of Stigma in the Design of Welfare Programs, May 2008

2306 Vesa Kanniainen and Paolo M. Panteghini, Tax Neutrality: Illusion or Reality? The Case of Entrepreneurship, May 2008

2307 Thomas Dohmen, Armin Falk, David Huffman and Uwe Sunde, The Intergenerational Transmission of Risk and Trust Attitudes, May 2008

2308 Guglielmo Maria Caporale and Mario Cerrato, Using Chebyshev Polynomials to Approximate Partial Differential Equations, May 2008

2309 Peter Egger and Doina Maria Radulescu, Labour Taxation and Foreign Direct Investment, May 2008

2310 Laurent Linnemer, Dissipative Advertising Signals Quality even without Repeat Purchases, May 2008

2311 Jordi Jofre-Monseny and Albert Solé-Ollé, Which Communities should be afraid of Mobility? The Effects of Agglomeration Economies on the Sensitivity of Firm Location to Local Taxes, May 2008 
2312 Andreas Haufler and Ferdinand Mittermaier, Unionisation Triggers Tax Incentives to Attract Foreign Direct Investment, May 2008

2313 Ronel Elul and Piero Gottardi, Bankruptcy: Is it enough to Forgive or must we also Forget?, May 2008

2314 Andreas Irmen and Johanna Kuehnel, Productive Government Expenditure and Economic Growth, May 2008

2315 Beate Henschel, Carsten Pohl and Marcel Thum, Demographic Change and Regional Labour Markets: The Case of Eastern Germany, May 2008

2316 Gabriel Felbermayr, Wido Geis and Wilhelm Kohler, Restrictive Immigration Policy in Germany: Pains and Gains Foregone?, May 2008

2317 Michael Hofmann, Gerhard Kempkes and Helmut Seitz, Demographic Change and Public Sector Budgets in a Federal System, May 2008

2318 Paul De Grauwe, Macroeconomic Modeling when Agents are Imperfectly Informed, June 2008

2319 Johann K. Brunner and Susanne Pech, Optimum Taxation of Inheritances, June 2008

2320 Thomas Eichner and Marco Runkel, Corporate Income Taxation of Multinationals in a General Equilibrium Model, June 2008

2321 Rainald Borck and Matthias Wrede, Subsidies for Intracity and Intercity Commuting, June 2008

2322 Patricia Apps and Ray Rees, Testing the Pareto Efficiency of Household Resource Allocations, June 2008

2323 Amihai Glazer, Vesa Kanniainen and Panu Poutvaara, Firms' Ethics, Consumer Boycotts, and Signalling, June 2008

2324 Claudia M. Buch, Jörg Döpke and Kerstin Stahn, Great Moderation at the Firm Level? Unconditional vs. Conditional Output Volatility, June 2008

2325 Helmuth Cremer, Philippe De Donder, Dario Maldonado and Pierre Pestieau, Forced Saving, Redistribution and Nonlinear Social Security Schemes, June 2008

2326 M. Hashem Pesaran and Paolo Zaffaroni, Optimal Asset Allocation with Factor Models for Large Portfolios, June 2008

2327 Harald Badinger and Peter Egger, Horizontal versus Vertical Interdependence in Multinational Activity, June 2008

2328 Jan K. Brueckner and Harris Selod, A Theory of Urban Squatting and Land-Tenure Formalization in Developing Countries, June 2008 
2329 Paolo M. Panteghini, Corporate Debt, Hybrid Securities and the Effective Tax Rate, June 2008

2330 Guglielmo Maria Caporale, Juncal Cuñado and Luis A. Gil-Alana, Modelling Long-Run Trends and Cycles in Financial Time Series Data, June 2008

2331 Avi Ben-Bassat and Momi Dahan, Social Identity and Voter Turnout, June 2008

2332 Martin R. West and Ludger Wößmann, "Every Catholic Child in a Catholic School”: Historical Resistance to State Schooling, Contemporary Private Competition, and Student Achievement across Countries, June 2008

2333 Erkki Koskela and Panu Poutvaara, Outsourcing and Labor Taxation in Dual Labor Markets, June 2008

2334 Philippe Choné and Laurent Linnemer, Optimal Litigation Strategies with Signaling and Screening, June 2008

2335 Albert Solé-Ollé and Pilar Sorribas-Navarro, Does Partisan Alignment Affect the Electoral Reward of Intergovernmental Transfers?, June 2008

2336 Antonio Cabrales and Piero Gottardi, Markets for Information: Of Inefficient Firewalls and Efficient Monopolies, June 2008

2337 Sumon Majumdar and Sharun W. Mukand, The Leader as Catalyst - on Leadership and the Mechanics of Institutional Change, June 2008

2338 Ulrich Hange, Tax Competition, Elastic Labor Supply, and Growth, June 2008

2339 Guy Laroque and Bernard Salanié, Does Fertility Respond to Financial Incentives?, June 2008

2340 Adriano Paggiaro, Enrico Rettore and Ugo Trivellato, The Effect of Extending the Duration of Eligibility in an Italian Labour Market Programme for Dismissed Workers, June 2008

2341 Helmut Seitz, Minimum Standards, Fixed Costs and Taxing Autonomy of Subnational Governments, June 2008

2342 Robert S. Chirinko, Leo de Haan and Elmer Sterken, Asset Price Shocks, Real Expenditures, and Financial Structure: A Multi-Country Analysis, July 2008

2343 Wolfgang Leininger, Evolutionarily Stable Preferences in Contests, July 2008

2344 Hartmut Egger and Udo Kreickemeier, Fairness, Trade, and Inequality, July 2008 